\title{
Fluorinated tracers for imaging cancer with positron emission tomography
}

\author{
Olivier Couturier ${ }^{1}$, André Luxen ${ }^{2}$, Jean-François Chatal ${ }^{1}$, Jean-Philippe Vuillez ${ }^{3}$, Pierre Rigo ${ }^{4}$, Roland Hustinx ${ }^{5}$ \\ ${ }^{1}$ Division of Nuclear Medicine, Hôtel Dieu, Nantes, France \\ ${ }^{2}$ Centre de Recherche du Cyclotron, University of Liège, Liège, Belgium \\ ${ }^{3}$ Division of Nuclear Medicine, Grenoble, France \\ ${ }^{4}$ Division of Nuclear Medicine, Hôpital Princesse Grace, Monte Carlo, Monaco \\ 5 Division of Nuclear Medicine, CHU, Liège, Belgium
}

\begin{abstract}
2- $\left[{ }^{18} \mathrm{~F}\right]$ fluoro-2-deoxy-D-glucose (FDG) is currently the only fluorinated tracer used in routine clinical positron emission tomography (PET). Fluorine-18 is considered the ideal radioisotope for PET imaging owing to the low positron energy $(0.64 \mathrm{MeV})$, which not only limits the dose rate to the patient but also results in a relatively short range of emission in tissue, thereby providing high-resolution images. Further, the 110-min physical half-life allows for high-yield radiosynthesis, transport from the production site to the imaging site and imaging protocols that may span hours, which permits dynamic studies and assessment of potentially fairly slow metabolic processes. The synthesis of fluorinated tracers as an alternative to FDG was initially tested using nucleophilic fluorination of the molecule, as performed when radiolabelling with iodine-124 or bromide-76. However, in addition to being long, with multiple steps, this procedure is not recommended for bioactive molecules containing reactive groups such as amine or thiol groups. Radiochemical yields are also often low. More recently, radiosynthesis from prosthetic group precursors, which allows easier radiolabelling of biomolecules, has led to the development of numerous fluorinated tracers. Given the wide availability of ${ }^{18} \mathrm{~F}$, such tracers may well develop into important routine tracers. This article is a review of the literature concerning fluorinated radiotracers recently developed and under investigation for possible PET imaging in cancer patients. Two groups can be distinguished. The first includes "generalist" tracers, i.e. tracers amenable to use in a wide variety of tumours and indications, very similar in this respect to FDG. These are tracers for non-specific cell metabolism, such as protein synthesis, amino acid transport, nucleic acid synthesis or membrane component synthesis. The second group consists of "specific" tracers for receptor expression (i.e. oestrogens or so-matostatin), cell hypoxia or bone metabolism.
\end{abstract}

Keywords: Positron emission tomography - Fluorinated tracers - Cancer imaging

\section{INTRODUCTION}

2- $\left[{ }^{18}\right.$ F]fluoro-2-deoxy-D-glucose (FDG) is currently the only positron emission tomography (PET) tracer used for routine cancer imaging. Its synthesis was published in 1975 and the first human images were obtained in 1976 [1]. The initial clinical indications were limited to the assessment of myocardial viability and the evaluation of suspected recurrent brain tumours. Thanks to the development of scanners with the capability to rapidly obtain high-quality images, PET has become a major player in the field of oncological imaging.

FDG-PET in oncology relies on research published by Warburg decades ago [2, 3] that showed increased glycolysis in tumour cells, with an increase in glucose metabolism and lactate production and a decrease in oxidative pathways. The simplified mechanism of uptake of FDG by tumour cells is now well understood: as a glucose analogue, FDG enters the cell membrane using the same transporters as glucose (GLUT); it is then phosphorylated into ${ }^{18}$ F-FDG-6-phosphate by the hexokinase. This metabolite is not a substrate for further enzymes and thus accumulates inside the cell, in proportion to the metabolism of glucose. Such accumulation of phosphor-ylated radiotracer creates a gradient between the tumour and surrounding tissues, highly favourable to the detection of cancer lesions.

In tumour cells, along with increased glycolysis, enhanced glucose (and FDG) transport contributes to the intracellular accumulation of the tracer. The increased glycolysis results from two key phenomena: firstly, the loss of the Pasteur effect, i.e. loss of the feedback loop decreasing the ATP production through the inhibition of several key enzymes of glycolysis, and secondly, a reorientation of the pentose pathways towards nucleotide synthesis instead of energy production. An increase in the number of glucose transport molecules (GLUT), in particular GLUT-1, present at the cell surface is responsible for the glucose transport towards tumour cells. The gene coding for GLUT-1, and to a lesser extent the gene for GLUT-3, are overexpressed in cancer cells, in parallel with (not secondary to) overexpression of several proto-oncogenes involved in cell proliferation. Hence, the overexpression of GLUT-1 stands among the features of malignant transformation, but its relationship with proliferation is only indirect [4]. A thorough discussion of the biological significance of FDG tumour uptake is 
beyond the scope of this article, but it should be noted that this aspect is far from being fully understood. For instance, the relative contribution of glycolysis and transport varies markedly according to the tumour type. Additionally, many other parameters influence the degree of FDG uptake by cancer cells. Tumour proliferation, hypoxia, fraction of inflammatory infiltrate and even blood glucose level all modify FDG uptake, and their precise contribution remains difficult to evaluate in individual tumours. For instance, FDG uptake is increased in macro-phages owing to the inflammatory infiltrate present in both malignant tumours and benign lesions [5-10].

Numerous alternative compounds have consequently been proposed, or are being evaluated, for better tumour characterisation. Fluorinated radiotracers appear to be the most attractive option, mainly due to the wide availability of ${ }^{18} \mathrm{~F}$ and the possibility of automated radiosyn-thesis. Some of these tracers are likely to enter the clinical field of oncology in the very near future. These new compounds can be divided into generalist tracers, i.e. evaluating non-specific aspects of the tumour metabolism, such as protein synthesis, amino acid (AA) transport, nucleic acid synthesis or membrane component synthesis, and specific tracers, dealing for instance with receptors or gene expression.

\section{FLUORINATED ANALOGUES OF AMINO ACIDS}

\section{Amino acid metabolism}

Various mechanisms are involved in the production, cell transport and protein incorporation of AAs. There are 20 known AAs, of which nine are called essential AAs, which cannot be synthesised and must be provided by the alimentation. The others can be obtained through in-tracellular recycling of proteins. AA uptake by the cells may vary according to general parameters such as intra-cellular concentration of various AAs, $\mathrm{pH}$ and temperature. Although AAs may simply diffuse into the cells, their transport principally depends on more than 20 ubiquitous membrane transport systems. Each system is responsible for the transport of one or more AAs. Two groups of transporters are identified: In sodium-dependent systems, the affinity of the catalytic site of the transport protein for the AA is enhanced following the linkage of a sodium ion. These systems depend upon the transmembrane sodium gradient and the membrane potential. They are responsible for transporting large neutral AAs, short side-chain AAs or non-ramified side-chain AAs, including alanine, serine and glycine. The most important sodium-dependent transporters are the systems A, ASC and Gly. The major sodium-independent system is the L-system, but several others exist, such as the systems $\mathrm{B}^{0,+}$ and $\mathrm{y}^{+}$. These transporters deal with aromatic AAs and ramified side-chain AAs, including leucine, valine, tyrosine and phenylalanine. In sodiumdependent systems, the direction of transport depends on the transmembrane gradient of AA concentration. However, as such a gradient can be created by sodium-independent systems, both transport systems are deeply intricate. Finally, other, non-ubiquitous, systems exist, such as the system T, which transports tyrosine, phenylalanine and tryptophan into the erythrocytes. The majority of these systems are capable of transporting synthetic or non-metabolisable AA analogues.

Once inside the cell, AAs can be incorporated into proteins, through the tRNA and ribosomes. However, they are not merely the building blocks for proteins. They are also precursors for many other biomolecules, such as hormones or neurotransmitters, and enter several metabolic cycles, for instance as methyl group donors. AAs can be degraded into urea, on the one hand, and metabolites transformable into glucose, fatty acids or ketone bodies, on the other hand, thus becoming sources of energy for the cell. Finally, they can also be recycled and utilised by other cells, a process that necessitates transmembrane transport.

\section{Tumour metabolism of amino acids and imaging}

Increased transport and/or protein synthesis in tumour cells was demonstrated more than 40 years ago [11]. In vitro, most tumours accumulate one or more AAs $[12,13]$, sometimes in competition with other classes of AA [14]. Enhanced transport function may be related to an overexpression of proteins, controlled by oncogenes and proto-oncogenes, especially for the system A [15]. However, it is more probably the simple consequence of higher cell demand for AAs related to increased needs for tumour growth. Hence a simplistic view would relate increased AA transport to sustenance of an increased protein synthesis rate (PSR), both phenomena reflecting

the level of tumour proliferation. This view is at best incomplete and partially correct, however, as a significant fraction of the protein synthesis is devoted to maintenance of vital cell functions, independently of proliferation. Furthermore, not all AAs are incorporated into newly formed proteins, as mentioned earlier [16]. Indeed, an increase in AA transport is possible even when protein synthesis is inhibited [17, 18].

Of the two mechanisms, increased transport and PSR, the former is likely to be the most important as regards PET imaging of tumours using radiolabelled AA analogues [19]. The intratumoural concentration is, however, limited by efflux of the tracer or its labelled metabolites. This phenomenon may be minimised by choosing nonmetabolisable compounds, without any efflux of labelled metabolites or with an efflux that is as limited as 
possible [19-22]. In addition, these tracers appear to be more specific for tumours than FDG, as the protein metabolism in inflammatory cells appears to be less modified than the glucose metabolism [23-25]. Nonetheless, several false positive results have been reported with tracers such as $\left[{ }^{11} \mathrm{C}\right.$-methyl]-methionine (MET) and L-3$\left[{ }^{123}\right.$ I] iodo- $\alpha$-methyltyrosine (IMT), for instance in sarcoid, abscess or angiomas or following irradiation [26, 27].

The literature classically refers to radiolabelled AA analogues aimed at measuring either membrane transport $[26,27]$ or PSR [28]. Most early studies and applications were performed using ${ }^{11} \mathrm{C}$-labelled compounds, the best-known being MET. However, the short physical half-life of ${ }^{11} \mathrm{C}$ prevents its use in most nuclear medicine departments (i.e. those without an on-site cyclotron). Moreover, the physical period is also very short with regard to both protein synthesis, which is a fairly long biological process, and the multiple purification steps required by the radiochemical synthesis. In addition, production costs are very high. Radiolabelling with ${ }^{18} \mathrm{~F}$ has thus generated great interest. Among the numerous ${ }^{18} \mathrm{~F}$-labelled AAs that are currently being investigated, tyro-sine has been under particular scrutiny, especially the following derivatives: 2- $\left.{ }^{18} \mathrm{~F}\right]$ fluoro-L-tyrosine (F-TYR), L-3$\left[{ }^{18} \mathrm{~F}\right]$ fluoro- $\alpha$-methyl tyrosine (FMT), $O$ - $\left(2-\left[{ }^{18} \mathrm{~F}\right]\right.$ flu-oroethyl)-L-tyrosine (FET) and $6-\left[{ }^{18} \mathrm{~F}\right]$-DOPA (FDOPA). The chemical structure of these compounds is shown in Fig. 1.

Fig. 1. Fluorinated analogues of amino acids<smiles>N[C@@H](Cc1ccc(O)cc1F)C(=O)O</smiles>

F-TYR<smiles>N[C@@H](Cc1ccc(OCCF)cc1)C(=O)O</smiles>

FET<smiles>NC(Cc1ccc(O)c(F)c1)(C(=O)O)C(=O)O</smiles>

FMT<smiles>N[C@@H](Cc1cc(O)c(O)cc1F)C(=O)O</smiles>

FDOPA

\section{$2-\left[{ }^{18}\right.$ F]fluoro-L-tyrosine}

In the first published F-TYR synthesis, in 1989, an $O$-acetyltyrosine group underwent an electrophilic fluorination on a triflate $\left(\mathrm{CF}_{3} \mathrm{CO}_{2} \mathrm{H}\right)$ [29]. The specific activity was reported as $10-20 \mathrm{MBq} / \mu \mathrm{mol}$, with a low radiochem-ical yield (17\%, which is actually obtained from a precursor). More recently, Lemaire et al. proposed a multiple-step procedure using another precursor, 2-trimethylam-monium-4-methoxy-benzaldehyde triflate, with a higher yield (25-40\% corrected for decay, $100 \mathrm{~min})$ and also higher specific activity [30].

Tyrosine and probably F-TYR are handled by the L-transport system, which is bidirectional, sodium independent and essentially reliant upon the AA trans-membrane gradient [31, 32]. Like its now well-documented ${ }^{11} \mathrm{C}$ labelled counterpart, L- $\left[1-{ }^{11} \mathrm{C}\right]$-tyrosine (TYR), F-TYR was initially proposed as a marker for PSR in tumour cells [29-33]. In mice, more than $80 \%$ of the compound is incorporated into newly formed cerebral proteins 60 min after tracer injection, with a low tRNA-bound fraction and few intracellular radiolabelled metabolites [29]. In humans, F-TYR uptake is significantly higher in primary cerebral tumours than in the normal cortex, with a better contrast obtained soon after tracer injection owing to the rapid rise in the plasma concentration of radiolabelled proteins [31] (Fig. 2). Further studies suggest, however, that transport is the primary mechanism responsible for the accumulation of F-TYR in tumour cells. Compartmental modelling applied to 15 patients with gliomas showed that $K_{1}$ is the most increased parameter in tumours as compared with normal tissues [31]. Ishiwata et al. systematically compared F-TYR, L- $\left[{ }^{3} \mathrm{H}\right]$ methyl-methionine and L-1- $\left[{ }^{14} \mathrm{C}\right]$ leucine $\left({ }^{14} \mathrm{C}\right.$-LEU) in tumour-bearing mice [34]. Although protein incorporation was high using all three tracers, ${ }^{14} \mathrm{C}$-LEU showed the faster PSR. Moreover, cyclohexo-midine, which is a selective inhibitor of protein synthesis, decreases ${ }^{14} \mathrm{C}$-LEU uptake but not F-TYR uptake, whereas transport blockade with ouabain decreases the uptake of all three tracers [17]. A recent clinical study reported somewhat disappointing results in terms of the sensitivity of F-TYR for detection of tumour lesions of various types, but interestingly enough there was a wide disparity between the levels of uptake of both FDG and F-TYR in some of the lymphoma patients, which may suggest prognostic implications [35]. 
Fig. 2. Left insular grade II astrocytoma. The lesion is seen as a focus of decreased activity, as compared with the cortex, on the FDG scan, and as a focus of increased activity on the F-TYR study

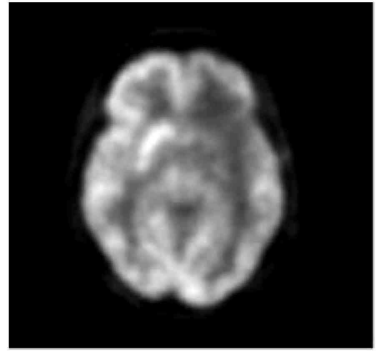

FDG

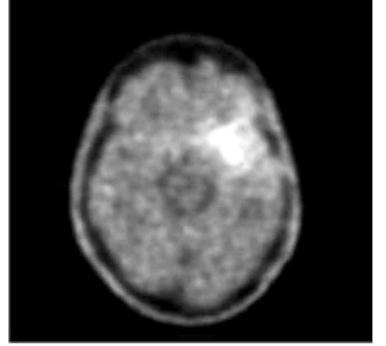

F-TYR

\section{L-3-[ ${ }^{18}$ F]fluoro- $\alpha$-methyl tyrosine}

FMT was first proposed in 1997 [36]. The radiosynthesis is based on non-specific radiofluorination with acetylhypofluorite; its specific activity and yields are very low. It accumulates more rapidly and intensely than FDG in animal tumour models $[37,38]$. FMT uptake relies essentially upon the large AA transport systems. Like the ${ }^{123}$ Ilabelled IMT, its incorporation into proteins is very limited $[38,39]$. The affinity for the transporters is, however, different for FMT and for $\alpha$-methyl derivatives [40-42]. Watanabe et al. compared FMT and FDG in a series of 75 patients with musculoskeletal tumours [43]. The tracers showed the same sensitivity (73\%), but FMT was significantly more specific than FDG (85\% vs 66\%). FMT performed better in distinguishing benign lesions from malignant tumours, whereas FDG was more accurate for grading the tumour lesions. Nevertheless, the sensitivity of FDG-PET was low in this study, and lower than that reported in most other studies, where it is consistently higher than $90 \%[44,45]$. The same group compared FMT and FDG in 19 patients with suspected or demonstrated malignancies and found 91\% sensitivity for FDG as compared with 74\% for FMT [46]. Larger studies are thus needed to establish whether FMT (and other AA analogues) can demonstrate sensitivity as high as FDG, while improving its specificity for cancer.

\section{O-(2-[ ${ }^{18}$ F]fluoroethyl)-L-tyrosine}

Like FMT and IMT, FET is a tracer of AA transport, without significant incorporation into newly formed proteins [47, 48]. The synthesis, which was developed in 1999 by Wester et al. [47] is fairly simple and straightforward. It is completed in no more than $1 \mathrm{~h}$, with high radiochemical yields (40\%) and specific activity. Tumour uptake is rapid, and no radiolabelled metabolites are detected in the blood up to $1 \mathrm{~h}$ after injection [49]. One major advantage of this tracer is that it appears highly specific for cancer. Rau et al. [50] compared the uptake of three tracers (FDG, MET and FET) in various animal models, including tumour, acute inflammation (lymphadenitis caused by concanavalin A) and chronic inflammation (streptozotocin-induced lymphadenitis). Whereas all three lesion types were highly avid for FDG and MET, only the tumours showed increased FET uptake as compared with controls. Few data exist in patients, however. Preliminary results in seven patients with disseminated melanomas suggest complementarities between FDG and FET, with some of the lesions negative with FET being positive with FDG and vice versa [51]. Another study in 16 brain tumour patients reported encouraging results, as all lesions were clearly seen with a high contrast and good correlation with MET uptake [52].

\section{$\left[{ }^{18}\right.$ F]fluoro-L-dihydroxyphenylalanine}

Dihydroxyphenylalanine (DOPA) is a tyrosine metabolite. It has been labelled with ${ }^{18} \mathrm{~F}$ in the position 2 (2FDOPA [53]) or 6 of the aromatic ring (6- ${ }^{18} \mathrm{~F}-\mathrm{L}-3$,4-fluorodihydroxyphenylalanine, 6-FDOPA [54]). As the yield is higher, and the synthesis process much simpler, with 6-FDOPA than with 2-FDOPA, only the former is in fact currently utilised. Large amounts of 6-FDOPA can be produced using a multistep reaction based on a nucleophilic substitution of an aromatic aldehyde. Alkyl-ation of protected glycine with radioactive benzyl bromide under phase transfer catalysis followed by an acidic deprotection gives 6-FOPA (C. Lemaire, personal communication). Both compounds use the L AA transport system to enter the cells. Uptake quantitation is hampered by the presence of circulating radiometabolites ( $O$-methyl-FDOPA), which may in turn re-enter the cells via the same transport system. 6-FDOPA is currently used to investigate the brain dopaminergic system in various movement disorders. Both the decarboxylation of the compound and the release into blood of ra- 
diometabolites can be reduced with carbidopa, a decar-boxylase inhibitor.

In oncology, FDOPA has been proposed as a biomark-er for melanomas. In an animal model, 2-FDOPA accumulated in melanomas and breast tumours, but the uptake was significantly higher in tumours with a high level of melanin synthesis $[55,56]$. However, Dimitrakopoulou-Strauss et al. clearly showed in melanoma patients that 6-FDOPA uptake is not related with melanogenesis, but rather depends on transport [57]. 6-FDOPA may therefore be envisaged as an oncological radiotracer, potentially complementary to FDG [58]. Recently, Hoegerle et al. have reported very encouraging results in infrequent tumours such as carcinoids, medullary thyroid carcinomas, phaeochromocytomas and glomus tumours [59,60]. It appears that the most accurate diagnosis is achieved using combinations of FDOPA and conventional methods, or FDOPA, FDG and conventional methods. FDOPA was also recently proposed as an alternative to MET for evaluation of primary brain tumours, the lesion/cortex activity ratios being very similar for the two compounds [61]. The sensitivity remains an issue, however, as reported in a series of patients with small cell lung cancer [62]. Indeed, the tumour to background contrast is generally lower with FDOPA than with FDG, as shown in Fig. 3.

Fig. 3. Stage IV non-small cell lung cancer. All lesions are visualised on both the FDG and the FDOPA studies (3D-projection images), but with a higher contrast with the former

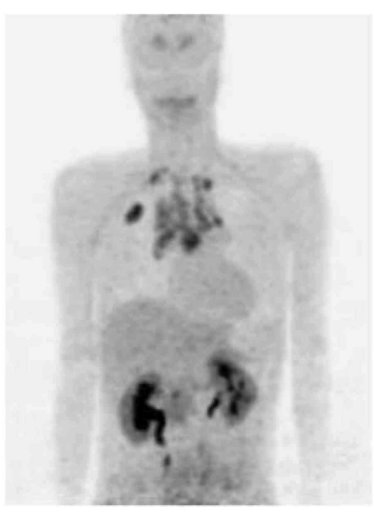

FDOPA

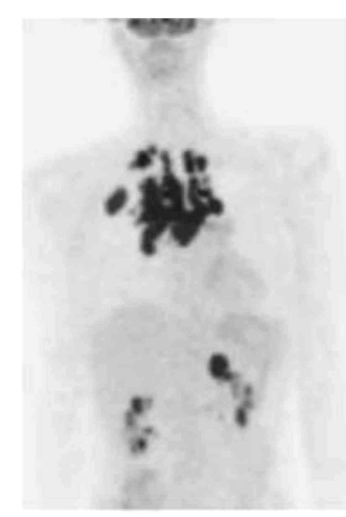

FDG 
Fig. 4. Fluorinated octreotide analogues

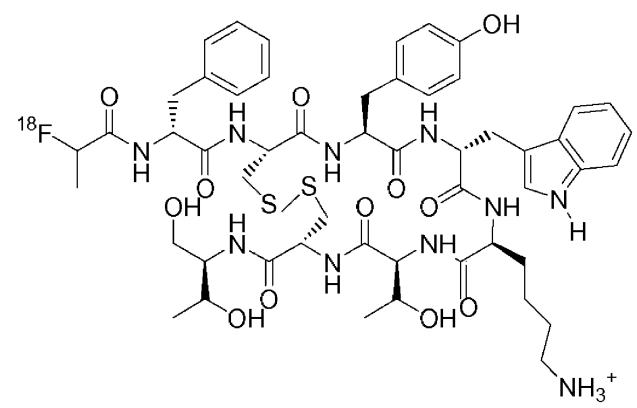

2-[ $\left[{ }^{18}\right.$ F]Fluoropropionyl-D-Phe ${ }^{1}$-octreotide

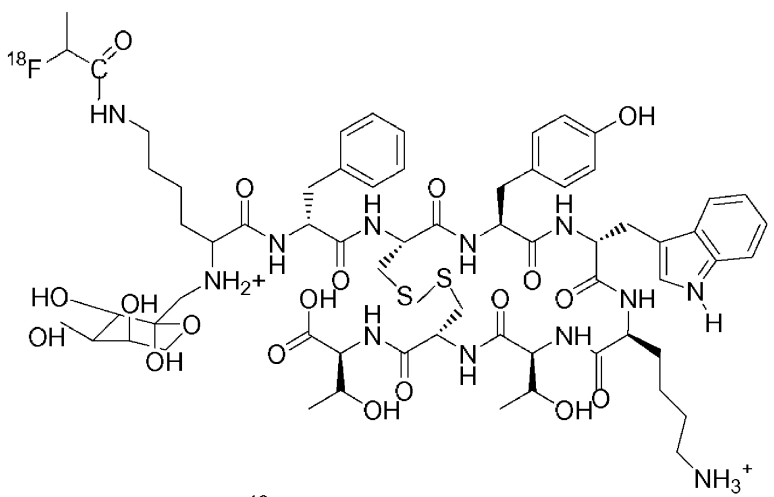

$\left[{ }^{18}\right.$ F]FP-Gluc-TOCA

\section{SOMATOSTATIN RECEPTOR IMAGING WITH FLUORINATED COMPOUNDS: $\left[{ }^{18}\right.$ F]FLUORO- OCTREOTIDE}

Somatostatin (SST) is a cyclic peptide whose two active forms consist of 14 and 28 AAs (SST14 and SST28). It is secreted in the brain (in particular but not exclusively in the hypothalamus), the digestive tract (D cells) and the thyroid (C cells). SST displays locoregional inhibitory hormonal properties on both the physiological and the tumour-related synthesis of growth hormone, insulin, glucagon and gastrin, as well as antiproliferative features, through modulation of the immune response and inhibition of angiogenesis. SST acts on tissues expressing membrane receptors (SSTRs), which consist of five different polypeptides (SSTR 1-5). All SSTR subtypes are activated trough the G protein system, but the end-effect of SST depends on the receptor subtype and the target tissue. SSTRs have been found in a wide variety of tumours, in particular neuroendocrine tumours, which mostly derive from the APUD system cells (amine precursor uptake and decarboxylation), but also brain, thyroid (medullary), lung cancers (small cell) and lym-phomas, among many others [63-75]. Various non-malignant diseases also show significant levels of SSTR expression, such as Graves' disease, rheumatoid arthritis and sarcoid [64].

Octreotide is an SST analogue with a longer biological half-life. It is metabolised in the liver. Hormonal properties of octreotide are close to those of SST in that it binds to the SRIF1-class SSRT (SRIF: somatotropin release inhibiting factor), which includes the SSTR2, SSTR3 and SSTR5 subtypes. Whereas the two active forms of SST have a similar affinity for all receptor subtypes, octreotide affinity is highest for SSTR2, and it does not bind significantly to the SRIF2-class SSRT (SSTR1 and SSTR4) [64, 76].

Octreotide is indicated for treatment of neuro-endocrine tumours such as carcinoids, VIPomas and glucagonomas, with an efficacy that is directly correlated with the level of SSRT expression in the tumour [77]. Radiolabelled SST analogues may thus be used for both diagnosis and therapy planning. Such analogues include ${ }^{123}$ I-Tyr ${ }^{3}$-octreotide [78], ${ }^{111}$ In-DTPA-D-Phe ${ }^{1}$-octreotide $\left({ }^{11}\right.$ In-pentetreotide) [79] and the newer technetium99m-labelled compounds [ $\left.{ }^{99 \mathrm{~m}} \mathrm{Tc}\right]-\mathrm{N}_{4}$-Bz-octreotide [80] and $\left[{ }^{99 \mathrm{~m}} \mathrm{Tc}\right]-P n A O-D-P h{ }^{1}$-octreotide $[81,82] .{ }^{111} \mathrm{In}$ pente-treotide is the only radiopharmaceutical routinely used in clinical practice, mainly for diagnosis, staging or follow-up of gastro-entero-pancreatic neuroendocrine tumours [83]. Several PET tracers are currently being 
investigated, mainly as dosimetric surrogates for beta-emitter compounds developed for therapy [84-87].

The first fluorinated octreotide analogue, 2- $\left[{ }^{18} \mathrm{~F}\right]$ fluo-ropropionyl-D-Phe ${ }^{1}$-octreotide [88] (Fig. 4), showed very poor biodistribution properties in rats, with low tumour uptake and high accumulation in the liver [89]. Recent studies demonstrate that conjugating analogues with carbohydrates improves the biodistribution, with decreased uptake by the fatty tissue, liver and plasma proteins, increased tumour uptake and renal excretion [90, 91]. Synthesis of the first carbohydrated derivative labelled with ${ }^{18} \mathrm{~F}(N(\alpha)$-(1-deoxy-D-fructosyl)-N( $(\varepsilon)-(2-$ $\left[{ }^{18} \mathrm{~F}\right]$ fluoropro-pionyl)-Lys $(0)-\mathrm{Tyr}(3)$-octreotide $\left(\left[{ }^{18} \mathrm{~F}\right] \mathrm{FP}\right.$-Gluc-TOCA $)$ was very recently reported by Wester et al. (Fig. 4). The synthesis is achieved within $3 \mathrm{~h}$, with radiochemical yields in the $30-40 \%$ range [92]. In rats, Wester et al. found that the tracer was rapidly excreted via the kidneys, with limited liver and bowel uptake and very high tumour accumulation (pancreatic carcinoma). In the same article, the authors reported on the first human study with $\left[{ }^{18} \mathrm{~F}\right] \mathrm{FP}$-Gluc-TOCA in a patient with liver metastases from a carcinoid tumour. All the known lesions were clearly visualised, with standardised uptake values (SUVs) ranging from 21 to 38, and an additional abdominal lesion was revealed. These results are encouraging but further studies are of course needed to assess the clinical performance of the tracer as well as its possible role as compared with other positron-emitting radiopharmaceuticals.

\section{FLUORINATED NUCLEOSIDES}

The level of proliferation is obviously a key parameter when it comes to characterisation of neoplastic lesions. The relationship between FDG uptake and proliferation is highly complex. Protein synthesis, as measured using radiolabeled AA analogues, only imperfectly and indirectly reflects cell proliferation. DNA synthesis is the process that is most reliably associated with proliferation. The effectiveness of tritiated thymidine in measuring DNA synthesis has been well documented, and it is indeed widely employed in in vitro studies. Thymidine has also been successfully labelled with ${ }^{11} \mathrm{C}$, and the tracer uptake is directly related to cell proliferation. However, use of ${ }^{11} \mathrm{C}$-thymidine is hampered by the short isotope half-life, the difficult radiosynthesis and the presence of circulating radiolabeled metabolites. Several alternative compounds, labelled with ${ }^{18} \mathrm{~F}$, have thus been proposed, including $3^{\prime}$-deoxy- $3^{\prime}$ - $\left.{ }^{18} \mathrm{~F}\right]$-fluorothymi-dine (FLT), ${ }^{18} \mathrm{~F}$-FBAU (1-(2-deoxy-2-fluoro-1- $\alpha$-D-ara-binofuranosyl)5 -bromouracil), ${ }^{18}$ F-FMAU (2'-fluoro-5-methyldeoxyuracil- $\beta$-D-arabinofuranosyl) and ${ }^{18} \mathrm{~F}$-FAU $(2$ 'fluorodeoxyuracil- $\beta$-D-arabinofuranosyl). FBAU, FMAU and FAU are, unlike FLT, incorporated into DNA. These tracers are still at a very early stage of development, and few data are available regarding their potential for whole-body imaging. We shall therefore concentrate our further discussion on FLT, which is increasingly well documented.

\section{Radiosynthesis of 3'-fluoro-3 '-deoxythymidine}

Unlabelled 3'-fluoro-3'-deoxythymidine has been recognised as an antiviral agent for more than 10 years [93].

The synthesis of FLT was first reported in 1991, but the low radiochemical yield prevented routine clinical use of the compound [94]. Since then, various precursors have been proposed, using various synthesis pathways. The first was 3- $N$-(2,4-dimethoxybenzyl)-1-[5-O-(4,4'-dimethoxytrityl)-3-O-nosyl-2-deoxy- $\beta$-D-lyxofuranosyl]thymine $[95,96]$ but the filtration of precipitate salts limits the possibility of developing automated production. Other obstacles arise when using another precursor, 5'-O-(4,4'-dimethoxytrityl)-2,3'-anhydrothymidine [97, 98], such as the high temperature for labelling, the low radiochemical yield and the use of non-volatile DMSO, which can interfere during the high-performance liquid chromatography (HPLC) purification. Currently, 3- $N$-Boc-1-[5$O$-(4,4'-dimethoxytrityl)-3-O-nosyl-2-deoxy- $\beta$-D-lyxofuranosyl] thymine $[99,100]$ appears to be the precursor of choice. The procedure is fairly simple, with a one-step hydrolysis in a homogeneous solution, without any filtration. The radiochemical yield is about $12 \%$ EOB (end of bombardment) and radiosynthesis time is 85 min. (hydrolysis $45 \mathrm{~min}$ and HPLC $40 \mathrm{~min}$ ). Furthermore, this process could easily be transposed and adapted to an FDG synthesiser. Figure 5 shows the chemical structure of FLT.

\section{Metabolism of FLT}

Nucleosides, including FLT, enter the cells by facilitated diffusion and by a carrier-mediated mechanism. Two types of transport molecule, es and $e i$, control the influx and efflux of nucleosides. FLT is a substrate for the es system [101]. Once inside the cell, nucleosides are phos-phorylated. Although four kinases are involved in the nucleoside metabolism, FLT is only handled by thymi-dine kinase TK1 and to a much lesser extent by TK2. The activity of the cytosolic isoenzyme TK1 is cell cycle dependent [102-105]. TK1 is genetically coded and its expression is controlled by the transcriptional factor E2F, which belongs to signal pathways regulating cell proliferation (retinoblastoma protein pathway, pRb) [106-110]. TK1 expression is strictly controlled in normal cells and is only enhanced in the late $\mathrm{G}_{1}$ phase and the $\mathrm{S}$ phase. It is much higher, by up to 15 -fold, in tumour cells, in which TK1 expression is also uncoupled from the DNA synthesis [111, 112, 113]. Moreover, on- 
cogenes may be activated through the $\mathrm{pRb}$ pathways, leading to E2F factor deregulation and abnormal TK1 expression $[108,109]$. TK1 overexpression is thus frequently observed in proliferating tumour cells.

Fig. 5. Chemical structure of FLT

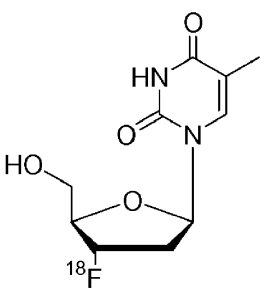

$\left[{ }^{18} \mathrm{~F}\right] \mathrm{FLT}$

\section{FLT uptake and cell proliferation}

TK1 has a high affinity for FLT, albeit lower than for thymidine. Toyohara et al. [114] studied 22 tumour cell lines composed of cells in various phases of their cycle. They obtained excellent correlations between FLT uptake and the proportion of cells in S-phase in each cell line.

The measurement of cell proliferation using $\left[{ }^{3} \mathrm{H}\right] \mathrm{TdR}$ relies on its accumulation both after phosphorylation by TK1 and after incorporation into DNA during replication. The monophosphorylated form of FLT (FLTMP) similarly accumulates inside the cells but there is no further phosphorylation to triphosphate derivatives. Some studies reported no incorporation of FLT into DNA [115-118] but recently the group in Ulm showed a significant in vitro incorporation in lymphoma and pancreatic cancer cell lines [119, 120]. Such conflicting results may be related to the experimental setting, and in any case all data confirm a clear relationship between FLT uptake, TK1 activity and proliferation in tumour cells. FLTMP can be hydrolysed into FLT by the 5'nucleoti-dase (5'-NT) and consequently leak out of the cells. This leakage is, however, merely potential; as it competes with high levels of phosphorylation by TK1, it is only responsible for a very limited reduction in intracellular accumulation of the compound [101].

Human studies reveal high bone marrow uptake of FLT, as well as significant liver and urinary tract distribution. The tracer is indeed glucuronidated in the liver before being excreted by the kidneys. Unlike FDG, FLT is not taken up by the normal cortex, which is clearly an advantage for evaluation of brain tumours. The radiation dosimetry of FLT in human PET studies was recently published and shows dose estimates compatible with routine clinical use (the $\left[{ }^{18} \mathrm{~F}\right] \mathrm{FLT}$ effective dose equivalent (mean $\pm \mathrm{SD}$ ) was $0.028 \pm 0.012 \mathrm{mSv} / \mathrm{MBq}$ for a standard male patient and $0.033 \pm 0.012 \mathrm{mSv} / \mathrm{MBq}$ for a standard female patient) [121].

Several clinical evaluations are now available for various cancer types in patients. Buck et al. [122] showed an excellent correlation between FLT uptake, as measured using the SUV, and the proliferative activity of 22 malignant lung tumours, as measured using Ki-67 im-munostaining. Furthermore, there was no significant FLT uptake in any of the eight benign lesions, and the sensitivity was $86 \%$, using visual interpretation. The same group further compared FLT and FDG in patients with various lung lesions and found that FLT has a better correlation with proliferative index, a higher specificity (no false positive results vs 4/8) and a slightly lower sensitivity (three false negative results vs one) than FDG [123]. Dittmann et al. studied 16 patients with various tumours and found a high sensitivity for FLT, although the uptake intensity was lower than with FDG [124]. Due to the high physiological uptake in the liver and the bone marrow, sensitivity may be limited for detection of metastases in these organs. This is emphasised by Francis et al., who studied patients with colorectal cancers with both FLT and FDG $[125,126]$. Although the primary tumours and lung and peritoneal metastases were well visualised, FLT missed the majority of the liver lesions (sensitivity $34 \%$ ).

These results indicate that FLT-PET is a potentially useful tool for diagnosis and staging, but its major impact should stem from its capability to evaluate early on the response to treatment. Barthel et al. reported good correlations between changes in FLT uptake and both the proliferative activity (by PCNA labelling) and the tumour volume changes in mice treated with the antipro-liferative drug 5-FU [127]. Although FDG uptake also decreased after treatment, these changes were less pronounced than with FLT. This issue remains to be carefully examined, as Dittmann et al. conversely reported an increased FLT uptake early on following incubation of cells derived from human squamous cell carcinoma with 5-FU and methotrexate [128]. This is explained by the wellknown induction of salvage pathways of DNA synthesis. Using another drug, cisplatin, the authors observed a rapid decrease in FLT uptake, which indicates that FLT needs to be carefully and systematically evaluated in 
various experimental models before FLT-PET is considered a valid method for assessing the response to treatment.

The specificity of the tracer is another aspect that needs further validation, as a false positive result has been reported in a sarcoid lesion [129]. Initial patient studies are, however, very encouraging, and animal experiments similarly show very limited FLT uptake in an E. coli infectious model [130].

In summary, there is tremendous interest in FLT among the nuclear medicine community, and validation of the tracer is well underway. Although several important issues remain unanswered, this tracer is clearly among the most promising developments for PET imaging.

\section{FLUORINATED ANALOGUES OF MEMBRANE PHOSPHOLIPIDS: CHOLINE ANALOGUES}

\section{Membrane lipid metabolism}

Membrane lipids can be grouped into two classes: phos-pholipids, with the diacylphosphoglycerides and the sphingolipids, on the one hand, and cholesterol, which is the only sterol present in cytoplasmic membrane, on the other hand. Phospholipids contain a polar group (substituted phosphoglycerol) and an apolar group (hydrocarbonated chain). The diacylphosphoglycerides derive from the esterification of glycerol by a phosphoric acid derivative, for instance phosphatidylcholine, which is the most frequently encountered in the membrane. The main constituent of sphingolipids is ceramide, a precursor for sphingophospholipids and sphingoglycolipids. Sphingomyelin, whose phosphated derivative is also phosphatidylcholine, is the most abundant sphingolipid in mammal's plasmic membranes.

Choline is a quaternary ammonium base. Even though choline is partly synthesised de novo, it also has to be found in the alimentation and it thus received the status of vitamin (group B) in 1998 from the US Food and Nutrition Board of the Institute of Medicine. It crosses the blood-brain barrier, protects the nerves' myelin sheath and is a precursor for acetylcholine. Choline therefore plays a primary role in the development and function of the brain. It is also one of the fundamental constituents of membrane phospholipids and contributes to the circulation of fatty acids and cholesterol through these membranes.

Choline enters the cell using specific transporters, both sodium dependent and sodium independent. The sodiumdependent system has a high affinity for choline (HACU, high-affinity choline uptake) and is located in the presynaptic nerve endings (acetylcholine synthesis). The sodium-independent system has a low affinity for choline; it is expressed in most cells and participates in the transport and intracellular concentration of choline, which is then rapidly phosphorylated into phosphatidyl-choline (whose intermediary metabolites are phosphorylcholine and cytidine-diphosphate-choline) or oxidated into betaine in the liver and kidneys. The first metabolite, phosphorylcholine, which results from the intervention of a choline kinase, remains trapped inside the cell.

The cell malignant transformation is associated with enhanced activity of the choline kinase, which is itself related to tumour proliferation and increased need for cy-toplasmic membrane constituents, in particular phospho-rylcholine and phosphatidylcholine $[131,132]$. De novo choline synthesis is slow in tumour cells, so that the increased uptake of radiolabelled choline may reflect the cell duplication rate [133].

\section{Fluorinated choline analogues}

Hara et al. pioneered the use of ${ }^{11} \mathrm{C}$-choline in man, which is now well documented [134]. Several tumours have been studied, including brain [135], lung [136], oesophagus [137], colon [134] and prostate [138]. In 1997, the same team proposed the automated synthesis of a flu-orinated choline analogue, 2- $\left[{ }^{18} \mathrm{~F}\right]$ fluoroethyl-dimethyl-2oxyethyl-ammonium $\left({ }^{18} \mathrm{~F}\right.$-fluoro-ethylcholine, FEC) [139]. However, this process is hampered by the necessity of eliminating Kryptofix 2.2.2, a catalyser that is toxic and cannot be administered to humans. To address this issue, DeGrado et al. developed the synthesis of $\left[{ }^{18} \mathrm{~F}\right]$-fluoroalkyl-dimethyl-2-hydroxyethyl-ammonium (methyl, ethyl, propyl), according to which $\left[{ }^{18} \mathrm{~F}\right]$ fluorobro-moalkane (methane, ethane, propane) is obtained using a gas chromatography $[140,141]$. The precursor, $\left[{ }^{18} \mathrm{~F}\right]$ flu-orobromomethane $(\mathrm{FBM})$, is produced by fluorination of dibromomethane catalysed by (Kryptofix 2.2.2/ $\mathrm{K}_{2}$ ) $\mathrm{CO}_{3}$. The radiochemical purity is higher than 99\% (HPLC) [142] and the yield is approximately 30-40\%, with a specific activity ranging from 37 to $185 \mathrm{MBq} / \mu \mathrm{mol}$ [141]. The radiolabelled compound remains highly stable after 2-h incubation in blood samples. Phosphoryla-tion rates were found to be similar for choline and its flu-orinated analogue $(\mathrm{FCH})$, which indicates that in vitro, $\mathrm{FCH}$ is also a substrate for the choline kinase [141]. It was shown in the same study that the uptake of choline and FCH was similar in human prostate cancer cells (PC-3), and that inhibition of transport and phosphoryla-tion using a specific inhibitor (hemicholinium-3, HC-3) decreased the uptake of FCH and choline by $89 \%$ and $45 \%$, respectively. The majority of FCH is actually retrieved in PC-3 cells as a phosphorylated metabolite (phosphoryl-fluorocholine), and there is no fluorinated derivative of betaine, which demonstrates the absence of significant oxidation of FCH. 
The biodistribution of both ${ }^{18} \mathrm{~F}$-fluorocholine and ${ }^{18} \mathrm{~F}$-fluoro-ethylcholine is very similar to that of choline, except for their very rapid urinary excretion [143]. Preliminary human studies are very encouraging, especially in the field of prostate cancer [144, 145]. Price et al. found that the FCH uptake was up to four times higher than FDG uptake in 18 patients with prostate cancer, whether androgen independent or androgen dependent (nine patients in each group) [145]. FCH detected more primary tumours and metastases, including to the skeleton, as compared to FDG. In another series of 16 patients with prostate carcinoma, Hara et al. found a similar level of uptake for FEC and ${ }^{11} \mathrm{C}$-choline, but the spatial resolution of FEC imaging was slightly superior owing to the shorter positron range for ${ }^{18} \mathrm{~F}$ as compared to ${ }^{11} \mathrm{C}$ [144]. It should be noted that these excellent results were obtained using bladder catheterisation to allow better visualisation of the prostate area.

DeGrado et al. also synthesised two other choline analogues [141]: [ $\left.{ }^{18} \mathrm{~F}\right]$ fluoropropyl-dimethyl-2-hydroxyethylammonium $\left({ }^{18} \mathrm{~F}\right.$-fluoropropylcholine; FPC) and $\left[{ }^{18} \mathrm{~F}\right]$ fluoromethyl-methylethyl-2-hydroxyethylammonium $\left({ }^{18}\right.$ F-fluoromethyl(ethyl)choline, FMEC). In in vitro experiments with the aforementioned PC-3 cell line, FMEC uptake was significantly lower (by approximately 50\%) than that of FCH and FPC. Conversely, the phosphorylation rate of FCH was twice as high as that of FPC. As pointed out by Hara et al. in an accompanying editorial, these results may have been influenced by potential contamination by dimethylethanolamine [133]. This compound, which is used during the synthesis according to DeGrado et al., is also an inhibitor of choline uptake by tumour cells both in vitro [146] and in vivo [147]. Such contamination was not sought in this study, and the properties of these two radiotracers should thus be further investigated.

In addition, little is known regarding the specificity of these tracers. Recently, Wyss et al. reported very high ${ }^{18} \mathrm{~F}$ fluorocholine uptake in an animal model of infection, which may limit its usefulness in routine imaging [148]. Nevertheless, given the high prevalence of prostate cancer and the absence of any satisfying PET tracer thus far, fluorinated choline analogues may well turn out to represent a major advance in the work-up of these tumours. The chemical structure of choline and fluorinated choline analogues is shown in Fig. 6.

Fig. 6. Choline and fluorinated analogues of choline<smiles>C[N+](C)(CCO)CCO</smiles>

$\left[{ }^{11}\right.$ C]choline<smiles>C[N+](C)(C[18F])CCO</smiles>

$\left[{ }^{18} \mathrm{~F}\right]$ fluorocholine $(\mathrm{FCH})$<smiles>C[N+](C)(CCO)CC[18F]</smiles>

$\left[{ }^{18} \mathrm{~F}\right]$ fluoroethylcholine (FEC)<smiles>C[N+](C)(CCCO)CCC[18F]</smiles>

[18F]fluoropropylcholine (FPC)<smiles>CC[N+](C)(CF)CCO</smiles>

[18F]fluoromethylethylcholine (FMEC)

\section{FLUORINATED ANALOGUES OF SEXUAL STEROIDS}

Sexual steroids act on sexual functions and determine the secondary sexual characteristics. Among the gonadal sexual steroids, oestrogens derive from the oestrane nucleus, progestins from the pregnane skeleton and androgens from the androstane skeleton. These hormones are synthesised in the gonads (testes and ovaries), adrenals, placenta and central nervous system (neurosteroids). Their secretion is controlled by the hypothalamic-hypophyseal axis. Gonadal synthetic pathways start with cholesterol being delivered to the cells by the plasma lipoproteins. The hormones are glucuronoconjugated in the liver and further eliminated by the kidneys.

\section{Fluorinated oestradiol derivatives}

Oestrogens play a major role in the development of breast cancer, as shown by epidemiological data and experimental findings concerning, for example, their mito-genic effect on established breast cancer cell lines or their capacity to induce breast cancer in animal models. Endocrine approaches, in particular using tamoxifen, are thus an important tool in the treatment of breast cancer. However, 30-40\% of all breast cancers do not express oestrogen receptors (ER-), and of the tumours with oestrogen receptors (ER+), up to 50\% will not respond to endocrine treatment. Conversely, $10 \%$ of ER- tumours will respond to such treatment. The ER status is assessed using immunohistochemistry analysis of tumour samples. It is believed that a non-invasive method which would accurately evaluate and quantify the presence of ER on the tumour and its metastases could better select patients for treatment and predict the therapeutic response. More than 20 fluorinated oestrogen derivatives have been 
proposed for this purpose.

Among these, $16 \alpha-\left[{ }^{18} \mathrm{~F}\right]$ fluoroestradiol-17 $\beta\left(\left[{ }^{18} \mathrm{~F}\right] \mathrm{FES}\right)$ has been the most actively investigated. Other compounds did not reach clinical development, either because of a lower affinity for ERs, as in the case of other 1fluorinated or 16-fluorinated derivatives [149], or because of a lower affinity for the sex binding globulin (SBG), as in the case of $16 \beta-\left[{ }^{18} \mathrm{~F}\right]$ fluoromoxestrol $\left(\left[{ }^{18} \mathrm{~F}\right] \beta \mathrm{FMOX}\right)[150]$. The affinity of the tracer for SBG is an important parameter, because oestradiol and its derivatives are transported in the bloodstream bound either to SBG or to albumin. SBG binding protects steroids against liver metabolism and ensures their transport to the target tissues. Moreover, their affinity for SBG also contributes to their cell uptake, through membrane receptors for SBG [151-153].

Other molecules are still at the preclinical level of development. This applies, for instance, to the difluoroestradiols, in which a second fluoride- 18 is added in position 2 or 4 of the FES molecule to improve the in vivo stability. However, the affinity for SBG is decreased in the process. The most promising compound in this class appears to be $4,16-\left[16 \alpha_{-1}{ }^{18} \mathrm{~F}\right]$ difluoro-11 $\beta$-methoxy-oestradiol, whose uptake by the uterus in immature female rats is higher than the $\left[{ }^{18} \mathrm{~F}\right] \mathrm{FES}$ uptake [154]. This tracer has yet to be clinically evaluated, however.

The synthesis of $\left[{ }^{18} \mathrm{~F}\right] \mathrm{FES}$ using trifluoromethane sul-phonate precursors (triflates) was first published in 1984 [149]. An alternative procedure, faster and more robust, used another cyclic sulphone as a precursor. This procedure was then automated, with an average radiochemical yield of $50 \%$, an $80-180 \mathrm{GBq} /$ micromole specific activity and a total duration of $50 \mathrm{~min}$ [155]. In rats and humans, about $95 \%$ of $\left[{ }^{18} \mathrm{~F}\right] \mathrm{FES}$ is bound to plasma proteins (either SBG or albumin) $[156,157]$. The non-specific binding rate to albumin is comparable to that of oestradiol, but the affinity to SBG is tenfold lower $[158,159]$. Even though most $\left[{ }^{18} \mathrm{~F}\right] \mathrm{FES}$ initially binds to albumin immediately after intravenous administration, very quickly thereafter (within less than 20 s) the tracer is transferred to SBG [158]. At equilibrium, $45 \%$ of the non-metabolised $\left[{ }^{18} \mathrm{~F}\right] \mathrm{FES}$ is bound to plasma SBG, and this fraction remains stable over time, which theoretically would allow delivery of a sufficient amount of tracer to image ER+ tissues. Furthermore, $\left[{ }^{18} \mathrm{~F}\right] \mathrm{FES}$ has high affinity to ERs [149, 160-162], which is, of course, indispensable for such a highly specific imaging method. However, other factors must be taken into account, as demonstrated by Mathias et al. in a mammary tumour model in rats [156]. These investigators found that the uptake of $\left[{ }^{18} \mathrm{~F}\right] \mathrm{FES}$ in ER+ tissues (uterine and mammary tumours) peaked early, less than $1 \mathrm{~h}$ after injection, with a slow decrease subsequently. However, ER+ tis-sues/ER- tissue activity ratios were only slightly positive immediately after tracer injection, and progressively increased over time to reach a maximum after $2-3 \mathrm{~h}$. This study suggested that parameters such as blood flow, binding kinetics, retention and wash-out of $\left[{ }^{18} \mathrm{~F}\right] \mathrm{FES}$ also intervene in the extent of the tracer gradient between ER+ tissues and ER- tissues, especially in small tumours. Moreover, the rapid in vivo metabolism of $\left[{ }^{18} \mathrm{~F}\right] \mathrm{FES}$ results in the formation of radiolabelled metabolites (glucuronidated and sulphate conjugates) that are not taken up by ER+ tumours, which further complicates quantitative analysis and contributes to the background activity seen on the images [157]. Mankoff et al. [157] suggested starting the image acquisition 20-30 min p.i. owing to the fast clearance of the tracer from the blood (only $20 \%$ of $\left[{ }^{18} \mathrm{~F}\right] \mathrm{FES}$ remains un-metabolised after $20 \mathrm{~min}$ ) and the fairly constant metabolite background after 20 min.

In human studies, $\left[{ }^{18} \mathrm{~F}\right] \mathrm{FES}$ has been used in breast cancer for the detection and staging of disease $[161,163]$, prediction of the response to treatment [164] and demonstration of the anti-oestrogenic effect of tamoxifen [165]. Dehdashti et al. found an $82 \%$ agreement between $\left[{ }^{18} \mathrm{~F}\right] \mathrm{FES}$ uptake and ER status of tumours: six tumours were $\left[{ }^{18} \mathrm{~F}\right] \mathrm{FES}+/ \mathrm{ER}+($ SUV 1.9 \pm 1.6$), 13$ tumours, $\left[{ }^{18} \mathrm{~F}\right] \mathrm{FES}-/$ ER- (SUV 0.5 \pm 0.2 ), and four tumours, $\left[{ }^{18} \mathrm{~F}\right] \mathrm{FES}-/ \mathrm{ER}+$. Eight benign lesions did not take up $\left[{ }^{18} \mathrm{~F}\right] \mathrm{FES}$ (SUV 0.6 \pm 0.2 ) [161]. In the same study but in a different series of 15 patients with pathology-proven disseminated disease (17 lesions), the concordance was $94 \%$ (9

$\left.\left[{ }^{18} \mathrm{~F}\right] \mathrm{FES}+/ \mathrm{ER}+, 7\left[{ }^{18} \mathrm{~F}\right] \mathrm{FES}-/ \mathrm{ER}-\right)$. In both series, FDG-PET was also performed, with $88 \%$ sensitivity and $100 \%$ specificity, but without any relationship between tracer uptake and ER status of the tumours. Two different patterns of $\left[{ }^{18} \mathrm{~F}\right] \mathrm{FES} / \mathrm{FDG}$ uptake are shown in Figs. 7 and 8. In another study, 53/57 metastases from breast cancer were identified using $\left[{ }^{18} \mathrm{~F}\right] \mathrm{FES}$ and PET (sensitivity 93\%), and the uptake had significantly decreased when measured an average of 17 days after initiating the anti-oestrogen treatment (tamoxifen or toremifen) [163]. A "metabolic flare" is sometimes observed and usually followed by clinical remission, but this may be confused with progressive disease, which would require salvage chemotherapy. Dehdashti et al. hypothesised that such metabolic changes associated with an agonist effect could be evidenced using a combination of FDG and $\left[{ }^{18} \mathrm{~F}\right] \mathrm{FES}$ PET imaging [165]. Indeed, in a small series (11 post-menopausal patients with biopsy-proven $\mathrm{ER}+$ metastatic breast cancer), $\left.{ }^{18} \mathrm{~F}\right] \mathrm{FES}$-PET and FDG-PET performed before and 7-10 days after initiation of tamoxifen treatment showed increased FDG uptake ("metabolic flare") and decreased FES uptake in the seven responding patients. In non-responding patients, FDG uptake did not change after treatment, $\left[{ }^{18} \mathrm{~F}\right] \mathrm{FES}$ uptake was lower on the baseline study than in responders, and the post-treatment decrease in $\left[{ }^{18} \mathrm{~F}\right] \mathrm{FES}$ uptake was also more limited. 
Fig. 7. Recurrent breast cancer (3D-projection images). The FDG PET study shows hypermetabolic lesions in the left axilla, whereas no focal uptake is seen on the $\left[{ }^{18} F\right] F E S$ study. (Courtesy of F. Bénard, University of Sherbrooke, Canada)

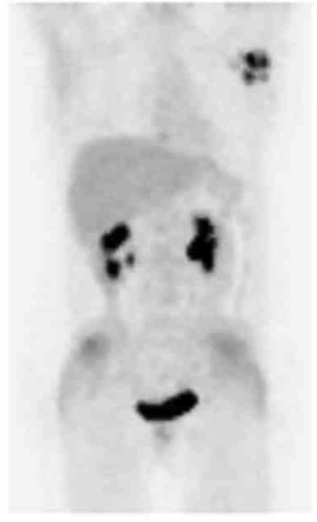

FDG

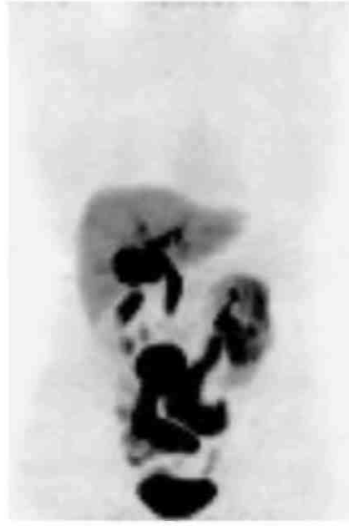

FES

Fig. 8. Metastatic breast cancer (3D-projection images). Most of the bone lesions that are clearly seen on the $\left[{ }^{18}\right.$ F]FES PET study are not visible on the FDG-PET study. (Courtesy of F. Bénard, University of Sherbrooke, Canada)

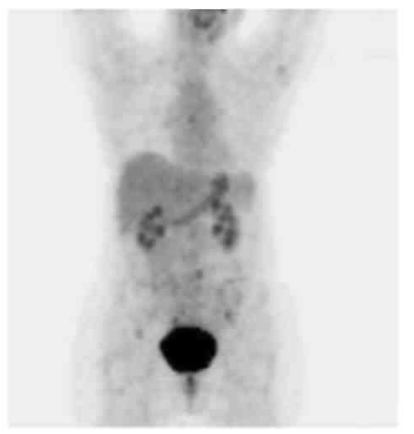

FDG

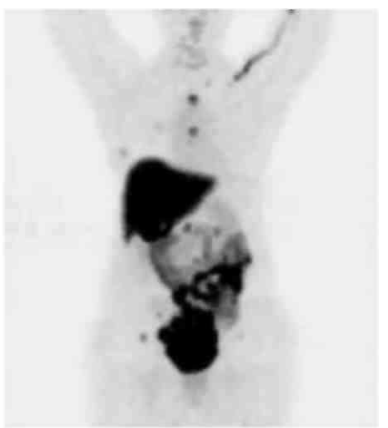

FES

\section{Fluorinated tracers of oestrogen sulphatase inhibitors: $\left[{ }^{18} \mathrm{~F}\right]$ fluoro-disulphamates}

Oestrogen sulphates are an important source of oestrogens for hormone-sensitive breast tumours. They are hydrolysed in tumours by an oestrogen sulphatase. Control over this enzyme activity, using sulphatase inhibitors (e.g. sulpha-mates), could lead to therapeutic improvements. Oestradiol disulphamate is among the most potent sulphamates.

The automated synthesis of a fluorinated analogue of oestradiol disulphamate, $16 \alpha\left[{ }^{18} \mathrm{~F}\right]$ fluoroestradiol-3, $17 \beta-$ disulphamate $\left(\left[{ }^{18} \mathrm{~F}\right] \mathrm{FESDS}\right)$, was published in 2001 [166]. The precursor is the cyclic sulphate used for the synthesis of $\left[{ }^{18} \mathrm{~F}\right] \mathrm{FES}[155,167]$. The synthesis is fast, about $1 \mathrm{~h}(+30 \mathrm{~min}$ for quality controls), with $11-15 \%$ radiochemical yields (20-25\% corrected for decay), and the specific activity may reach $400-500 \mathrm{GBq} / \mu \mathrm{mol}$.

In rats, Rodig et al. demonstrated a good correlation between $\left[{ }^{18} \mathrm{~F}\right] \mathrm{FESDS}$ uptake, oestrone sulphatase (ES) mRNA expression and ES enzymatic activity [168]. Biodistribution studies have been performed in various rodent models. In rats, the high blood concentration of the tracer suggested a significant reaction with another enzyme, carbon anhydrase (CA). Similarly, there was high uptake in organs with high CA activity, such as the spleen, heart, lungs and bone marrow [169]. Administering acetazolamide (an inhibitor of CA) decreased $\left[{ }^{18}\right.$ F]FESDS uptake by these organs, which confirmed the hypothesis. In mice, tumour uptake was highest in tumours with the highest CA activity, and it also decreased after administration of acetazolamide. Imaging and dynamic studies performed in pigs were rather disappointing, as only the bladder and the brain were seen on the images. Measurements on blood samples also showed high concentrations of the tracer. These preliminary studies, showing a higher affinity of $\left[{ }^{18} \mathrm{~F}\right]$ FESDS for CA than for ES, obviously reduce the potential clinical use of the tracer. To date, there have been no reports of human studies using this compound. 


\section{Fluorinated progesterone receptor ligands}

Several compounds have been developed for PET imaging of tumours expressing receptors for progesterone. Both 21- $\left[{ }^{18} \mathrm{~F}\right]$ fluoro-16 $\alpha$-ethyl-19-norprogesterone ([ $\left.\left.{ }^{18} \mathrm{~F}\right] \mathrm{FENP}\right)[170]$ and $21-\left[{ }^{18} \mathrm{~F}\right]$ fluoro-16 $\alpha$-methyl-19norprogesterone $\left(\left[{ }^{18} \mathrm{~F}\right] \mathrm{FMNP}\right)[171,172]$ showed high affinity for progesterone receptors in rodents $[170,172$ 174]. Human studies could not find any clinical role for these molecules, however. Indeed, rapid metabolism, high background activity and poor correlations between $\left[{ }^{18} \mathrm{~F}\right] \mathrm{FENP}$ uptake and progesterone receptor (PR) density in tumours all limited the potential applications in breast cancer imaging $[175,176]$. Further efforts to develop alternative compounds, such as $6 \alpha-\left[{ }^{18} \mathrm{~F}\right]$ fluoroprogesterone, labelled in position 6 , failed for similar reasons [177].

Finally, another family of tracers includes the $16 \alpha, 17 \alpha$-dioxolanes, labelled in position 4 [178, 179] or 21 [180]. They all show high affinity for PR, and favourable biodistribution in rodents, but none has yet been clinically evaluated in humans [178-180].

\section{Fluorinated androgen analogues}

Fluorinated androgen analogues have been proposed for imaging of tumours expressing androgen receptors (AR), in particular prostate cancer. The concept is very similar to the radiolabelled oestrogen analogues for breast cancer imaging. Prostate growth and differentiation is regulated by testosterone derivatives, i.e. dihydrotestoster-one, androstenedione and $5 \alpha$-androstenedione. In prostate tumours, AR-expressing cells coexist with AR-nega-tive cells, and there is a correlation between the level of AR expression in tumours and their response to hormone treatment [181-184], although the relationship between AR expression and overall prognosis is unclear [185]. Tumour biopsies, as well as transurethral resection, are prone to sampling errors and may thus misrepresent the actual distribution of AR+/AR- cells within the tumours. PET imaging with fluorinated AR ligands may thus represent an useful alternative.

Fluorinated derivatives labelled in position $16\left(16 \beta-\left[{ }^{18} \mathrm{~F}\right]\right.$ fluoro-testosterone, $16 \beta-\left[{ }^{18} \mathrm{~F}\right]$ fluoro-5 $\alpha$-dihydrotestosterone $\left(16 \beta-\left[{ }^{18} \mathrm{~F}\right] \mathrm{FDHT}\right), 16 \beta-\left[{ }^{18} \mathrm{~F}\right]$ mibolerone $\left(16 \beta-\left[{ }^{18} \mathrm{~F}\right] \mathrm{Fmib}\right)$, and $16 \alpha$ - and $16 \beta-\left[{ }^{18} \mathrm{~F}\right]$ fluoro- $7 \alpha-\mathrm{methyl}-19$ nortestosterone $)$ or in position $20\left(20-\left[{ }^{18} \mathrm{~F}\right]\right.$ fluoro-mibo-lerone $\left(\left[{ }^{18} \mathrm{~F}\right] \mathrm{Fmib}\right)$ and $20-\left[{ }^{18} \mathrm{~F}\right]$ fluoro-metribolone $)[152$, 181] all showed a satisfactory affinity for AR and good in vivo targeting in rats. The compounds labelled in position $16 \beta$ were rapidly defluorinated, however, resulting in high bone uptake and lower tumour uptake than with other derivatives [152]. Moreover, maximum plasma tracer concentration was reached too late to warrant consideration for clinical use.

Androgen analogues must combine a high affinity for SBG (for the same reasons as explained in the section on ER ligands) and a low affinity for PR, which are also expressed in some prostate tumours. It should be noted that SBG is present in all primates but not in mature rats, which may complicate the evaluation of these tracers [158]. $16 \beta-\left[{ }^{18} \mathrm{~F}\right] \mathrm{FDHT}$ has a high affinity for both AR and SBG $[152,186]$ whereas the affinity of mibolerone derivatives is high for ARs and low for PRs [181]. In baboons, Welch's group showed much higher prostate uptake with $16 \beta-\left[{ }^{18} \mathrm{~F}\right] \mathrm{FDHT}$ than with $16 \beta-\left[{ }^{18} \mathrm{~F}\right] \mathrm{Fmib}$ and $20-\left[{ }^{18} \mathrm{~F}\right] \mathrm{Fmib}$, whose affinity for SBG is low [187]. The same investigators demonstrated the protective role of SBG against the metabolisation of AR fluorinated ligands [188].

As an alternative, fluorinated derivatives of dihy-drotestoterone labelled in position 7 were recently developed, including $7 \alpha-\left[{ }^{18} \mathrm{~F}\right]$ fluoro-17 $\alpha$-methyl-5 $\alpha$-dihydro-testosterone $\left(\left[{ }^{18} \mathrm{~F}\right] \mathrm{MDHT}\right)[189,190]$. Labaree et al. showed that these fluorinated steroids have a high affinity for androgen receptors, in fact significantly higher than their iodinated counterparts. The most promising compound is $\left[{ }^{18} \mathrm{~F}\right] \mathrm{MDHT}$ because of its high affinity and biological activity in vitro as well as its high stability in aqueous medium at $37^{\circ} \mathrm{C}$ (whereas the iodinated analogue is rapidly metabolised) [189]. Prostate targeting was excellent in mature rats, with peak uptake reached as early as $1 \mathrm{~h}$ post injection and a slow decrease after $2 \mathrm{~h}$ [190]. These encouraging results remain to be confirmed in human studies, which may prove difficult as $\left[{ }^{18} \mathrm{~F}\right] \mathrm{MDHT}$ could be rapidly metabolised, owing to its low affinity for SBG [190]. To date, none of these fluori-nated androgen analogues has been clinically evaluated. Figure 9 shows the chemical structures of various fluori-nated analogues of steroids. 
Fig. 9. Fluorinated analogues of steroids<smiles>C[C@]12CCC3c4ccc(O)cc4CCC3C1C[C@H](F)[C@H]2O</smiles>

$\left[{ }^{18} \mathrm{~F}\right] \mathrm{FES}$

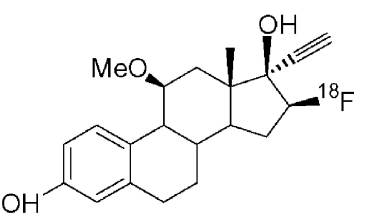

$\Gamma^{18}$ F $] \beta F M O X$<smiles>CC12CCC3c4ccc(OOS(N)(=O)=O)cc4CCC3C1C[C@H](F)[C@H]2OS(N)(=O)=O</smiles><smiles>CC[C@H]1CC2C3CCC4=CC(=O)CC[C@H]4[C@H]3CC[C@]2(C)[C@H]1C(=O)C[18F]</smiles>

$\left[{ }^{18}\right.$ F]FENP<smiles>C[C@H]1CC2=CC(=O)CC[C@]23CC[C@]2(C)C(C[C@H](F)[C@@]2(C)O)C13</smiles>

$16 \beta-\left[{ }^{18} \mathrm{~F}\right] \mathrm{Fmib}$<smiles>C[C@@H]1CC2C3CCC4=CC(=O)CC[C@H]4[C@H]3CC[C@]2(C)[C@H]1C(=O)C[18F]</smiles>

$\left[{ }^{18} \mathrm{~F}\right] \mathrm{FMNP}$<smiles>C[C@]12CCC3C(CC[C@@H]4CC(=O)CC[C@]34C)C1C[C@H](F)[C@H]2O</smiles>

$16 \beta-\left[{ }^{18} \mathrm{~F}\right] \mathrm{FDHT}$<smiles>C[C@]12CCC(=O)C[C@@H]1C[C@H](F)C1CC[C@@]3(C)O[C@@](C)(O)CCC3C12</smiles>

$\left[{ }^{18} \mathrm{~F}\right] \mathrm{MDHT}$

\section{FLUORINATED TRACERS FOR ASSESSING HYPOXIA}

\section{Cell hypoxia and resistance to treatment}

The role of oxygen concentration in the tumour response to irradiation has been known for a very long time. It is established that hypoxia to some extent protects tumour cells against irradiation and various chemotherapy agents such as mitomycin $\mathrm{C}$ and porfiromycin. Hypoxia induces the transcription of factor $1 \alpha$, which leads to the expression of genes that contribute to the cell adaptative response to hypoxia [191, 192]. This response includes an increase in the tumour vascularisation, resulting from the production of the vascular endothelium growth factor (VEGF) [193]. In parallel, there is a selection of cells with mutated p53 gene, which leads to blocking of apop-tosis pathways and to a genetic instability favouring the amplification of genes involved in the chemotherapy drug resistance [194-196]. These mechanisms result in an increased survival and proliferation potential for tumour cells. As such, hypoxia could be an important factor enhancing or triggering the resistance to treatment, particularly radiation therapy in numerous solid tumours. Several studies have shown a negative correlation between the hypoxic fraction and the response to irradiation in gliomas, cervical carcinomas, head and neck cancers and soft tissue sarcomas [192, 197-200]. Hypoxic cells can be found in virtually all solid tumours, but in numbers that vary with time and the pathological type [201]. Moreover, the proportion of hypoxic cells varies significantly for a given tumour, independently of its clinical or radiological presentation [202, 203].

\section{Assessment of tumour hypoxia and physiological bases of hypoxia tracers}

A method that could reliably, reproducibly and non-inva-sively measure the tumour hypoxic fraction would expedite the development of new therapeutic strategies specifically targeted against hypoxic cells. Moreover, it would be highly valuable as a pre-treatment prognostic indicator.

Currently the only available method relies on the use of Eppendorf needle measurement of oxygen partial pressure $\left(\mathrm{pO}_{2}\right)$ [204, 205]. Clinical studies using this technique showed significant correlations between $\mathrm{pO}_{2}$ and response to treatment $[192,198,206]$. However, the method has several limitations: it can only investigate superficial lesions and it cannot be routinely applied due to its invasiveness and practical considerations. For similar reasons, repeated measurements are difficult to obtain [206, 207]. Moreover, it cannot distinguish necrosis areas from anoxic but viable cells [208]. 
The sustained interest in the scientific literature in the development of non-invasive methods is therefore not surprising. Among these, radiolabelled nitroimida-zole derivatives have generated a large amount of data. 2Nitro-1H-imidazole (azomycin) was developed in the 1950s as an antibiotic targeted against anaerobic germs. Chapman et al. were the first to propose nitroimidazoles as bioreducible markers of hypoxia [209] and as a sensitising factor for radiation therapy of hypoxic tumours [210]. Nitroimidazoles are, in a hypoxic medium, reduced into reactive intermediary metabolites by intracel-lular reductases. This process is directly related to the hypoxia level, with production ratios of the reduced metabolites that can reach 40 times those observed in normoxic cells $[211,212]$. This phenomenon obviously creates a gradient highly favourable for specific detection of hypoxic cells [213]. Furthermore, these metabolites covalently bind to thiol groups of intracellular proteins and therefore accumulate within viable hypoxic cells [213, 214]. These complexes can be detected using various techniques, including monoclonal or polyclonal antibodies, magnetic resonance spectrometry, flow cytometry, autoradiography and scintigraphy, when the nitroimidazoles are radiolabelled [215-221].

\section{Radiolabelled misonidazole analogues}

2-Nitroimidazole can be labelled with fluorine-18, io-dine-123 and iodine-131 (iodinated azomycin arabino-side or IAZA), and technetium-99m. Among these, $\left[{ }^{18} \mathrm{~F}\right]$ fluoromisonidazole (FMISO) [222-224] and IAZA [209, $225,226]$ are the most extensively studied, with PET and SPECT, respectively.

$\left[{ }^{18} \mathrm{~F}\right]$ fluoromisonidazole

Grierson et al. proposed a two-step synthesis of 1H-1-(3-[ $\left[{ }^{18} \mathrm{~F}\right]$ fluoro-2-hydroxypropyl)-2-nitroimidazole ( $\left[{ }^{18} \mathrm{~F}\right]$ flu-oromisonidazole; FMISO) [227]. A fluoroalkylating agent ([ $\left.{ }^{18} \mathrm{~F}\right]$ epifluorohydrin) is first obtained from the $\left[{ }^{18} \mathrm{~F}\right]$ fluoride displacement of $(2 R)-(-)$ glycidyltosylate (GOTS). $\left[{ }^{18} \mathrm{~F}\right]$ FMISO is then prepared by reacting $\left[{ }^{18} \mathrm{~F}\right]$ epifluorohydrine with 2-nitroimidazole and subsequent HPLC purification. The average duration of the process has since been significantly shortened, from $140 \mathrm{~min}$ to $60 \mathrm{~min}$ [228]. This method produces $\left[{ }^{18} \mathrm{~F}\right]$ FMISO with high purity $(>99 \%)$, high yield $(40 \% \mathrm{EOB})$ and a $37 \mathrm{TBq} / \mathrm{mmol}$ specific activity. A simplified, 50-min single-step synthesis has also been proposed:

$\left[{ }^{18} \mathrm{~F}\right]$ FMISO ( $\left[{ }^{18} \mathrm{~F}\right] 3$-fluoro-1-(2'-nitro-1'-imidazolyl)-2-propanol) is produced with even higher yield $(55-80 \%)$ $[229,230]$. However, the precursor's synthesis is longer (five steps) than with Grierson's method.

Preliminary studies with tritiated and fluorinated derivatives of FMISO were performed at Washington University in Seattle from 1987 to 1990 . The first paper reported comparable uptake levels for $\left[{ }^{3} \mathrm{H}\right] \mathrm{FMISO}$ and $\left[{ }^{3} \mathrm{H}\right]$ misonidazole in vitro using hypoxic V-79 cells and in vivo using tumour-bearing mice [218]. The second article evaluated $\left[{ }^{18} \mathrm{~F}\right] \mathrm{FMISO}$ uptake in various tumour cell lines (V-79, EMT-6, RIF-1 and canine osteosarcoma) incubated under hypoxic conditions. The uptake ratio between hypoxic and normoxic cultures ranged from 12 to 27, depending on the tumour type. These experiments established in vitro the good selectivity of $\left[{ }^{18} \mathrm{~F}\right] \mathrm{FMISO}$ for hypoxic cells. Using various murine models, the authors also found a positive correlation between the tumour hypoxic fraction and $\left[{ }^{18} \mathrm{~F}\right] \mathrm{FMISO}$ uptake [231]. In a third publication, these investigators confirmed initial results from Chapman et al. [213]: the uptake inhibition in hypoxic cells is directly related to increased oxygen concentrations [232]. These three articles firmly established the relationship between $\left[{ }^{18} \mathrm{~F}\right] \mathrm{FMISO}$ uptake and the hypoxic fraction in tumours. Further experiments aimed to quantify this relationship with a view to allowing reliable measurement of the hypoxic fraction based on the intensity of uptake, thereby contributing to planning and evaluation of radiation therapy in humans. Various mathematical approaches have been tested both in vitro and in animal models, with results that were consistent with the hypoxic fraction as measured using cell survival curves and oxygen consumption [233-235]. A more conventional approach used the SUV, and found a negative exponential relationship between liver SUVs in pigs and the oxygen pressure in this organ [228]. Whatever the method, however, $\left[{ }^{18} \mathrm{~F}\right]$ FMISO uptake measurements underestimate hypoxia in severe conditions $\left(\mathrm{pO}_{2} \leq 2-3 \mathrm{mmHg}\right.$ ). This is probably related to the existence of a threshold below which bioreduction and cell uptake of $\left[{ }^{18} \mathrm{~F}\right] \mathrm{FMISO}$ cease to increase [235]. This hypothesis is consistent with the negative exponential relationship existing between $\left[{ }^{18} \mathrm{~F}\right] \mathrm{FMISO}$ uptake and tissue $\mathrm{pO}_{2}$, the threshold corresponding to the point at which the curve tends towards its asymptotes [236].

Following the initial feasibility studies performed in humans by Koh et al. [237] and Valk et al. [238], $\left[{ }^{18} \mathrm{~F}\right]$ FMISO has been used as a tracer for assessing myo-cardial ischaemia [239] and tumour hypoxia. Koh et al. first demonstrated fairly favourable uptake ratios between tumour and plasma, superior to 1.4 in six of eight patients before radiation therapy (and in all five with head and neck carcinoma). There was no uptake in the three patients who underwent a second PET study, after treatment [237]. The same year, Valk et al. visualised three gliomas with $\left[{ }^{18} \mathrm{~F}\right]$ FMISO and PET [238]. Further studies used $\left[{ }^{18} \mathrm{~F}\right] \mathrm{FMISO}$ to demonstrate hypoxia in head and neck carcinomas and their lymph node metastases (with a lower efficiency in the latter case) [240], non-small cell lung cancers [224] and soft tissue sarcomas [241]. Various methods have been proposed for quantification of uptake and thus hypoxia. Koh et al. [242] defined the hypoxic fraction volume (FHV) as the percentage of tumour pixels whose uptake was at least 1.4-fold higher than that of plasma, 120 min post injection. The authors 
showed a significant decrease in FHV after irradiation (from $58 \%$ before to $22 \%$ after treatment, median values) as well as the absence of any relationship between tumour volume and FHV before treatment. However, while one patient did not show any tumour uptake after treatment, the FHV remained unchanged in two other patients, suggesting that radiation therapy protocols should be adapted according to the level of hypoxia observed in each patient in order to limit the resistance to treatment. The same group confirmed these preliminary results in 37 patients with various malignant diseases, including 21 NSCLC and seven head and neck carcinomas. Ninetyseven percent of the tumours accumulated $\left[{ }^{18} \mathrm{~F}\right] \mathrm{FMISO}$, but with a high variability among tumour types and at different tumour sites in the same patient [224]. Such heterogeneity was also reported in comparative studies with both $\left[{ }^{18} \mathrm{~F}\right]$ FMISO and FDG in animals [243] and humans [241]. In 19 patients with soft tissue sarcomas, there was no relationship between FHV and VEGF expression, tumour grade or volume. In 10/19 patients who benefited from neo-adjuvant chemotherapy, the pixel by pixel correlation between $\left[{ }^{18} \mathrm{~F}\right] \mathrm{FMISO}$ and FDG uptake was 0.46 and 0.32 , before and after treatment, respectively, even though the uptake in most tumours decreased with both tracers after chemotherapy. This study underscores the value of using alternative tracers, and particularly $\left[{ }^{18} \mathrm{~F}\right] \mathrm{FMISO}$, for tailoring of an-ticancer treatments.

Other fluorinated misonidazole analogues

Another compound, 4- $\left[{ }^{18} \mathrm{~F}\right]$ fluoro-2,3-dihydroxy-1-2(2'-nitro-1'-imidazolyl)butane $\left(\left[{ }^{18} \mathrm{~F}\right]\right.$ fluoroerythroimidazole or $\left.\left[{ }^{18} \mathrm{~F}\right] \mathrm{FETNIM}\right)$, has been largely investigated by researchers at the University of Turku in Finland. The tracer is obtained by nucleophilic substitution with fluorine-18 of the tosylate group of the precursor (1-(2'-nitro- $1^{\prime}$ imidazolyl)-2,3-O-isopropylidene-4-tosyloxybutane). It was initially proposed by Yang et al. [214] and slightly modified by the Finnish investigators [244]. The synthesis is completed within 50 min, with a radiochemical purity superior to $95 \%$, and $13-20 \%$ radiochemical yields (corrected for decay) and a specific activity in the range of $330 \mathrm{GBq} / \mu \mathrm{mol}[244]$. In vivo studies using a rat mammary cancer model showed tumour/blood and tumour/muscle uptake ratios higher than those obtained with $\left[{ }^{18}\right.$ F]FMISO [214]. There was significant liver and tumour uptake, and no binding to plasma proteins and no peripheral metabolism, which explains the primarily urinary excretion of the unmodified compound. The low uptake by fat, brain and bone tissues suggests good in vivo stability of the molecule and absence of defluorina-tion [244]. The only human studies were performed in head and neck cancers [245-247]. They showed more favourable tumour/muscle uptake ratios than had been reported with $\left[{ }^{18} \mathrm{~F}\right] \mathrm{FMISO}$. The uptake was also more variable, however, related to the variations in tumour blood flow, as measured using $\left[{ }^{15} \mathrm{O}\right] \mathrm{H}_{2} \mathrm{O}$ and PET [245].

Various methods have been tested for quantification of $\left[{ }^{18} \mathrm{~F}\right]$ FETNIM uptake, including dynamic analyses developed by Patlak and Blasberg [248] and Logan [249], the SUV and the tumour/blood or tumour/muscle uptake ratios. Quantitative methods depended upon too many unverifiable parameters and were thus not validated, whereas the tumour/plasma uptake ratios provided the best estimates for tumour hypoxia [247]. The uptake ratios appear more favourable for $\left[{ }^{18} \mathrm{~F}\right] \mathrm{FETNIM}$, a hy-drophilic compound, than for $\left[{ }^{18} \mathrm{~F}\right] \mathrm{FMISO}$, and its synthesis is also simpler. Few studies are available, however, and the encouraging initial results remain to be confirmed on a larger scale.

Etanidazole derivatives are another class of fluorinat-ed derivatives of 2-nitroimidazole. In 1997, Tewson et al. developed the synthesis of $\left[{ }^{18} \mathrm{~F}\right]$ fluoroetanidazole ( $\left[{ }^{18} \mathrm{~F}\right]$ FETA) from a 2,3,5,6-tetrafluorophenyl ester of 2nitroimidazole. In vitro, $\mathrm{pO}_{2}$ inhibited both $\left[{ }^{18} \mathrm{~F}\right] \mathrm{FETA}$ and $\left[{ }^{18} \mathrm{~F}\right] \mathrm{FMISO}$ cell uptake, to a similar extent. In mice, the only significant difference between the two compounds was lower liver uptake and a lower amount of circulating and urinary metabolites with $\left[{ }^{18} \mathrm{~F}\right] \mathrm{FETA}[250]$. $\left[{ }^{18} \mathrm{~F}\right] \mathrm{EF} 1\left(\left[{ }^{18} \mathrm{~F}\right]-2-(2-n i t r o-1 \mathrm{H}-\mathrm{imidazol}-1-\mathrm{yl})-N-(3-\right.$ fluoropropyl)-acetamide) is a molecule comparable to $\left[{ }^{18} \mathrm{~F}\right] \mathrm{FETA}$, except that it bears an additional carbon on the side chain. The synthesis was published in 1999 [251]. $\left[{ }^{18} \mathrm{~F}\right] \mathrm{EF} 1$ is in fact a 3-monofluorinated analogue of a pentafluorinated molecule, EF5 [2-(2-nitro-1H-imi-dazol-1-yl)- $N$-(2,2,3,3,3-pentafluoropropyl)-acetamide], which is used for measurement of hypoxia by immuno-histochemistry [252] and flow cytometry [253]. EF5, like 2-nitroimidazole, binds to intracellular proteins following hypoxia-dependent bioreduction by cell nitroreductases. Taking advantage of the immunological properties of protein-EF5 conjugates, monoclonal antibodies such as ELK2-4 [215] and ELK3-51 [254] have been developed. More recently, a fluorinated analogue of EF5 was synthesised by electrophilic fluorination of 2-(2-ni-tro-1H-imidazol-1-yl)- $N$-(2,3,3-trifluoroallyl)-acetamide [255]. Both compounds, $\left[{ }^{18} \mathrm{~F}\right] \mathrm{EF} 1$ and $\left[{ }^{18} \mathrm{~F}\right] \mathrm{EF} 5$, have been studied in rats, using two tumour models, the hypoxic Morris 7777 or Q7 and the aerobic 9LF [256, 257]. Both tracers were excreted predominantly via the urinary tract, and only the hypoxic Q7 tumours were clearly visualised. The uptake was also directly related to the level of hypoxia, as measured using Eppendorf needles and immunohistochemistry. To date, no published data are available regarding these compounds in human studies. Figure 10 shows the chemical structure of fluorinated tracers of hypoxia.

Among the other fluorinated tracers for hypoxia, 4-bromo-1-(3- $\left[{ }^{18} \mathrm{~F}\right]$ fluoropropyl)-2-nitroimidazole (4- $\mathrm{Br}$ $\left.\left[{ }^{18} \mathrm{~F}\right] \mathrm{FPN}\right)$ and 1-(3-[ $\left[{ }^{18} \mathrm{~F}\right]$ fluoropropyl)-2-nitroimidazole ([ $\left.\left[{ }^{18} \mathrm{~F}\right] \mathrm{FPN}\right)$ [258] should also be mentioned, even though these compounds are still at a very preliminary step of development. 
Fig. 10. Fluorinated tracers for assessing hypoxia<smiles>O=[N+]([O-])c1nccn1CC(O)F</smiles>

FMISO<smiles>O=C(Cn1ccnc1[N+](=O)[O-])NCCF</smiles>

FETA<smiles>O=[N+]([O-])c1nccn1CC(O)C(O)CF</smiles>

FETNIM

\section{SODIUM FLUORIDE: $\left[{ }^{18} \mathrm{~F}\right] \mathrm{NAF}$}

The complex $\left[{ }^{18} \mathrm{~F}\right] \mathrm{NaF}$ dissociates in the blood into $\mathrm{Na}^{+}$and $\left[{ }^{18} \mathrm{~F}\right]$ fluoride ions. The uptake of $\left[{ }^{18} \mathrm{~F}\right]$ fluoride is related to bone metabolism, and results from ionic exchanges between hydroxyl groups of hydroxylapatite to form fluoroapatite. Both the blood flow and the osteo-blastic activity influence the $\left[{ }^{18} \mathrm{~F}\right]$ fluoride accumulation, in proportions that are still under discussion. $\left[{ }^{18} \mathrm{~F}\right] \mathrm{NaF}-\mathrm{PET}$ imaging, using appropriate modelling, could thus noninvasively assess bone metabolism.

$\left[{ }^{18} \mathrm{~F}\right]$ fluoride was introduced in 1962, and very early on was proposed as an osseous radiotracer [259]. The synthesis is very simple. $\left[{ }^{18} \mathrm{~F}\right]$ fluoride is rendered isoton-ic with an $\mathrm{NaCl}$ solution to form $\left[{ }^{18} \mathrm{~F}\right] \mathrm{NaF}$. The accumulation of $\left[{ }^{18} \mathrm{~F}\right]$ fluoride in osteoblastic areas of bone me-tastases was shown in autopsy series and in rabbit experimental models [260]. In patients with secondary hyper-parathyroidism, the $\left[{ }^{18} \mathrm{~F}\right]$ fluoride incorporation rate was correlated with the plasma parathormone level and with the bone formation rate $[261]$. In mice, $\left[{ }^{18} \mathrm{~F}\right] \mathrm{NaF}$ PET clearly identified fractures as foci of increased uptake at up to 7 weeks after the initial trauma, as well as human bone grafts in mice 2 months after the implantation and osteoblastic lesions induced by human prostate cancer cells (LAPC-9) [262]. Lytic lesions from human prostate cancer cells (CL-1 and PC-3) were visualised either as foci of globally increased activity or, more frequently, as rim-like foci, surrounding the edge of the lesions. Quantitative uptake, measured as cps/pixel per minute, was fairly reproducible in femoral and humeral regions of interest drawn on four studies over a period of 4 weeks. In patients with bone metastases from breast cancer, all lesions were visualised on PET as hot spots, whether they were osteolytic, osteoblastic or mixed on CT or MRI [263, 264]. However, there was no correlation between uptake intensity and bone density as measured with CT, with sometimes a very high $\left[{ }^{18} \mathrm{~F}\right]$ fluoride uptake localised in osteolytic areas. In the same study, foci of increased activity on bone scintigraphy using a Tc-labelled compound corresponded to foci on PET, but single-photon scintigraphy displayed limited spatial resolution and was also acquired in planar mode only, so that a lesion by lesion analysis was impossible. Schirrmeister et al. have shown higher diagnostic accuracy of $\left[{ }^{18} \mathrm{~F}\right] \mathrm{NaF}-\mathrm{PET}$ over both planar and SPECT scintigraphy for staging the skeleton in breast and nonsmall cell lung carcinoma $[4,265,266]$. In the most recent article, the difference in sensitivity was only significant for planar imaging (78\% sensitivity), whereas SPECT (94\%) and PET (99\%) provided similar results, without any impact of the latter on patient management [267]. The exact role of $\left[{ }^{18} \mathrm{~F}\right] \mathrm{NaF}-\mathrm{PET}$ in the diagnostic armamentarium of bone metastas-es remains to be established, especially given the wide availability of less expensive techniques such as bone scintigraphy and SPECT, and the performance of MRI. An example of bone metastases is shown in Fig. 11. 
Fig. 11. $\boldsymbol{a}, \boldsymbol{b}\left[{ }^{18} \mathrm{~F}\right] \mathrm{NaF}$ PET study (a coronal slice, $\boldsymbol{b}$ sagittal slice, $\boldsymbol{c}$ transaxial slice, $\boldsymbol{d} 3 D$ projection image) showing a bone metastasis in the left sacro-iliac joint. Additional lesions (ribs and left iliac bone) are also clearly visible on the $3 D$-projection image

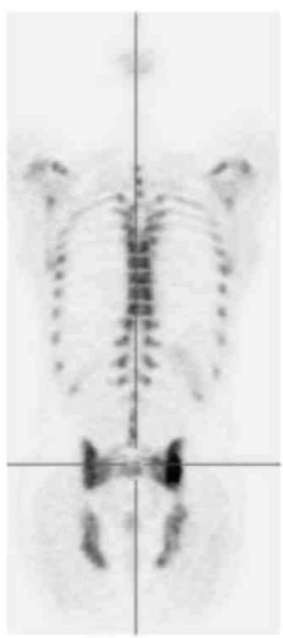

A

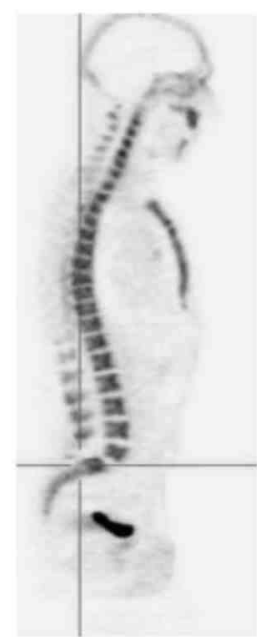

B

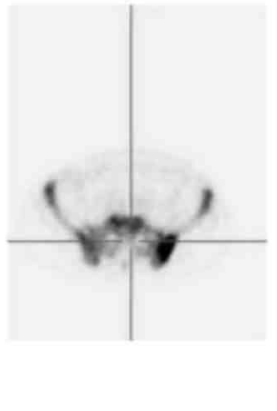

C

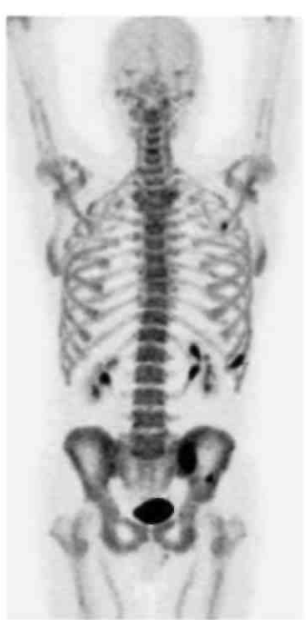

D

Fig. 12. Chemical structure of 5-FU<smiles>O=c1cc(F)c(F)c[nH]1</smiles>

\section{$\left[{ }^{18} \mathrm{~F}\right]-5$-fluorouracil: 5- $\left[{ }^{18} \mathrm{~F}\right] \mathrm{FU}$}

At the end of the 1950s, 5-fluorouracil (5-FU) was the first pyrimidine analogue proposed as an antitumour agent $[268,269]$. Alone or in combination with other drugs, 5-FU has been used in various types of cancer, including colorectal, breast and head and neck. Several mechanisms explain the antitumour properties of 5-FU, but its toxicity stems from the incorporation of the phos-phorylated form into nucleotides, in place of uracil. 5-FU belongs to the class of the antimetabolite agents, because its principal action is to inhibit the TS enzyme involved in the metabolism of nucleic acids. It is quickly catabolised in the liver into 5,6-dihydrouracil $\left(\mathrm{FUH}_{2}\right)$, an inactive derivative which is eliminated by the kidneys.

Numerous radiosynthesis pathways have been published for $5-\left[{ }^{18} \mathrm{~F}\right]$-fluorouracil $\left(5-\left[{ }^{18} \mathrm{~F}\right] \mathrm{FU}\right)$, in parallel with animal studies, starting as long ago as 1973 [270-275]. Various fluorinating agents have been proposed, with various purification methods [270, 271, 276-279], and the first automated and rapid synthesis was published in 1989 by Visser et al. [279]. The radio-chemical yield was approximately $70 \%$, and a $740 \mathrm{MBq}(20 \mathrm{mCi})$ sample of $5-\left[{ }^{18} \mathrm{~F}\right] \mathrm{FU}$ was obtained with a specific activity of $37 \mathrm{GBq} / \mu \mathrm{mol}(1 \mathrm{Ci} / \mu \mathrm{mol})$. More recently, similar results were obtained using a two-step proton-ic irradiation, in order to produce larger quantities of flu-orine-18, and with the major advantage of producing lower amounts of non-labelled uracil during the synthesis [280] (Fig. 12).

Biodistribution studies in rodents showed very rapid blood clearance (biological half-life 2 min), liver catabolism and both biliary and urinary excretion of fluorinated metabolites [281]. In tumour-bearing animals, 5$\left[{ }^{18} \mathrm{~F}\right] \mathrm{FU}$ was incorporated into tumour nucleotides, with a tumour uptake higher than that in the spleen, liver and small intestine [282]. Although preliminary studies suggested a relationship between $5-\left[{ }^{18} \mathrm{~F}\right] \mathrm{FU}$ uptake and tumour response to treatment in animal models [273], further experiments failed to confirm such results [274, 275, 283]. Shani et al. showed that pretreatment with 5-FU influenced the elimination of 5- $\left[{ }^{18} \mathrm{~F}\right] \mathrm{FU}$, which suggests different catabolic pathways before and after treatment, capable of modifying the quantity of radiotracer available for the tumours [284]. It is possible to block the catabo-lism of 5-FU with eniluracil (5-ethynyluracil), which inactivates a key enzyme, dihydropyrimidine dehydroge-nase [285]. Tumour SUVs and tumour to plasma, 
liver and kidney activity ratios were doubled using this method in tumour-bearing rats [286]. Also, Visser et al. demonstrated that the retention time of the tracer was longer in tumours responding to 5-FU than in nonresponding lesions [279, 287].

Initial studies reported a very similar biodistribution in humans and rats [275, 283]. However, biliary excretion is somewhat more variable, with significant differences among patients [288]. 5-[ $\left.{ }^{18} \mathrm{~F}\right] \mathrm{FU}$ has primarily been investigated in humans with the aim of predicting the response to chemotherapy with 5-FU. Dynamic studies have been performed in patients with liver metastases from colorectal cancer, using intra-arterial [289] or intravenous injection of the tracer [290-293]. The group in Heidelberg has the largest experience in the field. They have shown that: (1) uptake by metastases is highly variable from one patient to another and, within a single patient, from one lesion to another [291-293]; (2) most metastases show a low level of accumulation, so that lesions are faintly visualised as defects inside an otherwise highly tracer-avid liver parenchyma [291, 292]; and (3) there is a positive correlation between $5-\left[{ }^{18} \mathrm{~F}\right] \mathrm{FU}$ uptake by the tumour at baseline and the subsequent response to treatment $[292,294]$. Recent studies have investigated the effect of eniluracil on tracer uptake by liver metastas-es from colon cancer. Preliminary results obtained in small series indicated increased tumour uptake, with concomitant lower liver and renal uptake, resulting from the lower metabolisation of the tracer [295, 296].

Obviously, since the scope of this review was so broad, difficult choices had to be made. In particular, tracers for gene expression were left aside, as we felt they would deserve a complete article. Other research avenues are being actively pursued, such as the development of fluorinated radiotracers for assessment of $\alpha(v) \beta 3$ integrin expression, which plays a major role in tumour growth and tumour-induced angiogenesis [297-299].

\section{CONCLUSION}

The success of FDG as a general tracer for characterising and staging a wide variety of cancers has rejuvenated nuclear medicine and created new demands and opportunities. This should form the basis for efforts to capitalise on the future widespread availability of positron hybrid systems (PET/CT) and cyclotrons in order to consolidate and develop areas already covered by nuclear medicine using single-photon tracers. Such examples include substituting $\left[{ }^{18} \mathrm{~F}\right] \mathrm{NaF}$ for diphosphonates for bone scanning and replacing ${ }^{111} \mathrm{In}$ or ${ }^{99 \mathrm{~m}} \mathrm{Tc}$-labelled ligands by ${ }^{18} \mathrm{~F}$ la-belled ligands for receptor scintigraphy. Fluorinated tracers need to be developed for indications in which FDG has proven unsuccessful or suboptimal, primarily the evaluation of frequent cancers such as prostate cancer or well-differentiated tumours. In addition, tracers offering improved specificity (differentiation between tumoural and inflammatory lesions) and tracers designed to permit effective monitoring of treatment response need to be sought. This review provides evidence that progress in meeting these goals is well underway, and that such advances will contribute to the growing success of PET.

\section{References}

1. Alavi A, Reivich M. Guest editorial: the conception of FDG-PET imaging. Semin Nucl Med 2002;32:2-5.

2. Warburg O. The metabolism of tumors. London: Arnold Constable; 1930. p. 75-327.

3. Warburg O. On the origin of cancer cells. Science 1956; 123:309-14.

4. Schirrmeister H, Kuhn H, Guhlmann A, et al. Immunostaging in pancreatic cancer and chronic active pancreatitis: does in vivo FDGuptake correlate with proliferative activity? J Nucl Med 2001;42:721-5.

5. Kubota R, Kubota K, Yamada S, et al. Intratumoral distribution of fluorine-18-fluorodeoxyglucose in vivo: high accumulation in macrophages and granulation tissues studied by microautoradiography. J Nucl Med 1992;33:1972-80.

6. Brown RS, Leung J Y, Fisher SJ, et al. Intratumoral distribution of tritiated fluorodeoxyglucose in breast carcinoma: I. Are inflammatory cells important? J Nucl Med 1995; 36:1854-61.

7. Higashi K, Clavo AC, Wahl RL. In vitro assessment of 2-fluo-ro-2-deoxy-D-glucose, L-methionine and thymidine as agents to monitor the early response of a human adenocarcinoma cell line to radiotherapy. J Nucl Med 1993;34:773-9.

8. Lewis P, Salama A. Uptake of fluorine-18-fluorodeoxyglucose in sarcoidosis. J Nucl Med 1994;35:1647-9.

9. Minn H, Clavo AC, Grenman R, et al. In vitro comparison of cell proliferation kinetics and uptake of tritiated fluoro-deoxyglucose and Lmethionine in squamous-cell carcinoma of the head and neck. J Nucl Med 1995;36:252-8.

10. Patz EF Jr, Lowe VJ, Hoffman JM, et al. Focal pulmonary abnormalities: evaluation with F-18 fluorodeoxyglucose PET scanning. Radiology 1993;188:487-90.

11. Johnstone RM, Scholefield PG. Amino acid transport in tumor cells. Adv Cancer Res 1965;9:143-226.

12. Isselbacher KJ. Sugar and amino acid transport by cells in culture-differences between normal and malignant cells. N Engl J Med 1972;286:929-33.

13. Bush H, Davis JR, Honig GR, et al. The uptake of a variety of amino acids into nuclear proteins of tumors and other tissues. Cancer Res 1959;19:1030-9.

14. Wiseman G, Ghadially FN. Studies in amino-acid uptake by RD3 sarcoma cell suspensions in vitro. Br J Cancer 1955; 9:480.

15. Saier MH, Daniels GA, Boerner P, et al. Neutral amino acid transport systems in animal cells: potential targets of oncogene action and regulators of cellular growth. J Membr Biol 1988;104:1-20.

16. Souba WW, Pacitti AJ. How amino acids get into cells: mechanisms, models, menus and mediators. J Parenter Enteral Nutr 1992;16:569-78.

17. Ishiwata K, Kubota K, Murakami M, et al. Re-evaluation of amino acid PET studies: can the protein synthesis rates in brain and tumor tissues be measured in vivo? J Nucl Med 1993;34:1936-43. 
18. Daemen BJ, Zwertbroek R, Elsinga PH, et al. PET studies with L- $\left[1-{ }^{11} \mathrm{C}\right]$ tyrosine, L-[methyl- $\left.{ }^{11} \mathrm{C}\right]$ methionine and ${ }^{18} \mathrm{~F}-\mathrm{fluorodeoxyglucose}$ in prolactinomas in relation to bromo-cryptine treatment. Eur J Nucl Med 1991;18:453-60.

19. Miyagawa G, Oku T, Uehara H, et al. Facilitated amino acid transport is upregulated in brain tumors. J Cereb Blood Flow Metab 1998;18:500-9.

20. Martarello L, McConathy J, Camp M, et al. Synthesis and biological evaluation of Syn and Anti FMACBC, new amino acids for tumor imaging with PET. J Label Compd Radio-pharm 2001;44:S385-7.

21. Shoup TM, Olson J, Hoffman JM, et al. Synthesis and evaluation of [ $\left.{ }^{18} \mathrm{~F}\right] 1$-amino-3-fluorocyclobutane-1-carboxylic acid to image brain tumours. J Nucl Med 1999;40:331-8.

22. Uehara H, Miyagawa T, Tjuvajev J, et al. Imaging experimental brain tumors with 1-aminocyclopentane carboxylic acid and alphaaminoisobutyric acid: comparison to fluoro-deoxyglucose and diethylenetriaminepentaacetic acid in morphologically defined tumor regions. J Cereb Blood Flow Metab 1997;17:1239-53.

23. Kubota K, Yamada K, Yoshioka S, et al. Differential diagnosis of idiopathic fibrosis from malignant lymphadenopathy with PET and F18 fluorodeoxyglucose. Clin Nucl Med 1992; 17:361-3.

24. Kubota K, Matsuzawa T, Fujiwara T, et al. Differential diagnosis of AH109A tumor and inflammation by radioscintigra-phy with L[methyl- ${ }^{11}$ C]methionine. Jpn J Cancer Res 1989; 80:778-82.

25. Kubota R, Kubota K, Yamada S, et al. Methionine uptake by tumor tissue: a microautoradiographic comparison with FDG. J Nucl Med 1995;36:484-92.

26. Kole AC, Plaat BE, Hoekstra HJ, et al. FDG and L- $\left[1-{ }^{11} \mathrm{C}\right]$-tyrosine imaging of soft-tissue tumors before and after therapy. J Nucl Med 1999;40:381-6.

27. Kuwert T, Morgenroth C, Woesler B, et al. Uptake of iodine-123-alpha-methyl tyrosine by gliomas and non-neoplastic brain lesions. Eur J Nucl Med 1996;23:1345-53.

28. Vaalburg W, Coenen HH, Crouzel C, et al. Amino acids for the measurement of protein synthesis in vivo by PET. Int J Radiat Appl Instrum B 1992;19:227-37.

29. Coenen HH, Kling P, Stocklin G. Cerebral metabolism of L- $\left[2-{ }^{18}\right.$ F $]$ fluorotyrosine, a new PET tracer of protein synthesis. J Nucl Med 1989;30:1367-72.

30. Lemaire C, Gillet S, Kameda M. Enantioselective synthesis of 2-[ ${ }^{18}$ F]fluoro-L-tyrosine by catalytic phase-transfer alkylation. J Label Compd Radiopharm 2001;44:S857-9.

31. Wienhard K, Herholz K, Coenen HH, et al. Increased amino acid transport into brain tumors measured by PET of L- $\left(2-{ }^{18} \mathrm{~F}\right)$ fluorotyrosine [see comments]. J Nucl Med 1991; 32:1338-46.

32. Saier MH Jr. A functional-phylogenetic system for the classification of transport proteins. J Cell Biochem 1999; Suppl 33-34:84-94.

33. Daemen BJ, Elsinga PH, Ishiwata K, et al. A comparative PET study using different ${ }^{11} \mathrm{C}$-labelled amino acids in Walker 256 carcinosarcoma-bearing rats. Int J Rad Appl Instrum B 1991;18:197-204.

34. Ishiwata K, Kubota K, Murakami M, et al. A comparative study on protein incorporation of L-[methyl- $\left.\left.{ }^{3} \mathrm{H}\right] \mathrm{methionine,} \mathrm{L-[1-}{ }^{14} \mathrm{C}\right] \mathrm{leucine}$ and L-2- $\left[{ }^{18}\right.$ F]fluorotyrosine in tumor bearing mice. Nucl Med Biol 1993;20:895-9.

35. Hustinx R, Lemaire C, Jerusalem G, et al. Whole-body tumor imaging using PET and 2- ${ }^{18}$ F-fluoro-L-tyrosine: preliminary evaluation and comparison with ${ }^{18}$ F-FDG. J Nucl Med 2003; 44:533-9.

36. Tomiyoshi K, Amed K, Muhammad S, et al. Synthesis of isomers of ${ }^{18}$ F-labelled amino acid radiopharmaceutical: position 2- and 3-L${ }^{18} \mathrm{~F}$-alpha-methyltyrosine using a separation and purification system. Nucl Med Commun 1997;18:169-75.

37. Amano S, Inoue T, Tomiyoshi K, et al. In vivo comparison of PET and SPECT radiopharmaceuticals in detecting breast cancer. J Nucl Med 1998;39:1424-7.

38. Inoue T, Tomiyoshi K, Higuichi T, et al. Biodistribution studies on L-3-[fluorine-18]fluoro-alpha-methyl tyrosine: a potential tumordetecting agent. J Nucl Med 1998;39:663-7.

39. Langen KJ, Roosen N, Coenen HH, et al. Brain tumor uptake of L-3-[ $\left.{ }^{123} \mathrm{I}\right]$ iodo-alpha-methyl tyrosine: competition with natural L-amino acids [see comments]. J Nucl Med 1991; 32:1225-9.

40. Lahoutte T, Caveliers V, Dierickx L, et al. In vitro characterization of the influx of 3-[ $\left.{ }^{125} \mathrm{I}\right]$ iodo-L-alpha-methyltyrosine and 2-[ $\left.{ }^{125} \mathrm{I}\right]$ iodoL-tyrosine into U266 human myeloma cells: evidence for system T transport. Nucl Med Biol 2001;28:129- 34.

41. Lahoutte T, Caveliers V, Franken PR, et al. Increased tumor uptake of 3- ${ }^{123}$ I-Iodo-L-alpha-methyltyrosine after preloading with amino acids: an in vivo animal imaging study. J Nucl Med 2002;43:1201-6.

42. Lahoutte T, Mertens J, Caveliers V, et al. Comparative bio-distribution of iodinated amino acids in rats: selection of the optimal analog for oncologic imaging outside the brain. J Nucl Med 2003;44:1489-94.

43. Watanabe H, Inoue T, Shinozaki T, et al. PET imaging of mus-culoskeletal tumours with fluorine-18-methyltyrosine: comparison with fluorine-18 fluorodeoxyglucose PET. Eur J Nucl Med 2000;27:1509-17.

44. Schluter B, Bohuslavizki KH, Beyer W, et al. Impact of FDG PET on patients with differentiated thyroid cancer who present with elevated thyroglobulin and negative ${ }^{131}$ I scan. J Nucl Med 2001;42:71-6.

45. Dehdashti F, Siegel BA, Griffeth LK, et al. Benign versus malignant intraosseous lesions: discrimination by means of PET with 2-[F18]fluoro-2-deoxy-D-glucose. Radiology 1996; 200:243-7.

46. Inoue T, Koyama K, Oriuchi N, et al. Detection of malignant tumors: whole-body PET with fluorine 18 alpha-methyl tyrosine versus FDG-preliminary study. Radiology 2001; 220:54-62.

47. Wester HJ, Herz M, Weber W, et al. Synthesis and radiophar-macology of $O-\left(2-\left[{ }^{18} \mathrm{~F}\right]\right.$ fluoroethyl)-L-tyrosine for tumor imaging. J Nucl Med 1999;40:205-12.

48. Heiss P, Mayer S, Herz M, et al. Investigation of transport mechanism and uptake kinetics of $O$ - $\left(2\right.$ - $\left[{ }^{18} \mathrm{~F}\right]$ fluoroethyl)-L-tyrosine in vitro and in vivo. J Nucl Med 1999;40:1367-73.

49. Weber WA, Ott K, Becker K, et al. Prediction of response to preoperative chemotherapy in adenocarcinomas of the esopha-gogastric junction by metabolic imaging. J Clin Oncol 2001; 19:3058-65.

50. Rau FC, Weber WA, Wester HJ, et al. $O-\left(2-\left[{ }^{18} \mathrm{~F}\right]\right.$ fluoroethyl)-L-tyrosine (FET): a tracer for differentiation of tumour from inflammation in murine lymph nodes. Eur J Nucl Med 2002; 29:1039-46.

51. Schreckenberger M, Kadalie C, Enk A, et al. First results of F-18-fluoroethyl-tyrosine PET for imaging of metastatic malignant melanoma. J Nucl Med 2001;42:30P.

52. Weber WA, Wester HJ, Grosu AL, et al. O-(2-[ $\left[{ }^{18} \mathrm{~F}\right]$ fluoro-ethyl)-L-tyrosine and L-[methyl- $\left.{ }^{11} \mathrm{C}\right]$ methionine uptake in brain tumours: initial results of a comparative study. Eur J Nucl Med 2000;27:542-9.

53. Ishiwata K, Ido T, Takahashi T, et al. Feasibility study of fluorine-18 labeled dopa for melanoma imaging. Int J Rad Appl Instrum B 1989;16:371-4.

54. Luxen A, Perlmutter M, Bida GT, et al. Remote, semiautomated production of $6-\left[{ }^{18} \mathrm{~F}\right]$ fluoro-L-dopa for human studies with PET. Int J Rad Appl Instrum A 1990;41:275-81.

55. Ishiwata K, Kubota K, Kubota R, et al. Selective 2-[ $\left.{ }^{18} \mathrm{~F}\right]$-fluorodopa uptake for melanogenesis in murine metastatic melanomas. J Nucl Med 1991;32:95-101. 
56. Kubota R, Yamada S, Ishiwata K, et al. Active melanogenesis in non-S phase melanocytes in B16 melanomas in vivo investigated by double-tracer microautoradiography with ${ }^{18} \mathrm{~F}$-fluorodopa and ${ }^{3} \mathrm{H}$-thymidine. Br J Cancer 1992;66:614-8.

57. Dimitrakopoulou-Strauss A, Strauss LG, Burger C. Quantitative PET studies in pretreated melanoma patients: a comparison of 6-

$\left[{ }^{18} \mathrm{~F}\right]$ fluoro-L-dopa with ${ }^{18} \mathrm{~F}$-FDG and ${ }^{15} \mathrm{O}$-water using compartment and noncompartment analysis. J Nucl Med 2001; 42:248-56.

58. Graham MM. Combined ${ }^{18}$ F-FDG-FDOPA tumor imaging for assessing response to therapy. J Nucl Med 2001;42:257-8.

59. Hoegerle S, Altehoefer C, Ghanem N, et al. Whole-body ${ }^{18} \mathrm{~F}$ dopa PET for detection of gastrointestinal carcinoid tumors. Radiology 2001;220:373-80.

60. Hoegerle S, Altehoefer C, Ghanem N, et al. ${ }^{18} \mathrm{~F}$-DOPA positron emission tomography for tumour detection in patients with medullary thyroid carcinoma and elevated calcitonin levels. Eur J Nucl Med 2001;28:64-71.

61. Becherer A, Karanikas G, Szabo M, et al. Brain tumour imaging with PET: a comparison between $\left[{ }^{18} \mathrm{~F}\right]$ fluorodopa and $\left[{ }^{11} \mathrm{C}\right] \mathrm{methionine}$. Eur J Nucl Med Mol Imaging 2003;30:1561-7.

62. Jacob T, Grahek D, Younsi N, et al. Positron emission tomography with $\left[{ }^{18} \mathrm{~F}\right] \mathrm{FDOPA}$ and $\left[{ }^{18} \mathrm{~F}\right] \mathrm{FDG}$ in the imaging of small cell lung carcinoma: preliminary results. Eur J Nucl Med Mol Imaging 2003;30:1266-9.

63. Krenning EP, Bakker WH, Kooij PPM, et al. Somatostatin receptor scintigraphy with indium-111-DTPA-D-Phe-octreotide in man: metabolism, dosimetry and comparison with iodine-123-Tyr-3-octreotide. J Nucl Med 1992;33:652-8.

64. Krenning EP, Kwekkeboom DJ, Bakker WH, et al. Somatosta-tin receptor scintigraphy with $\left[{ }^{111}\right.$ In-DTPA-D-Phe]- and [ ${ }^{123}$ I-Tyr3]octreotide: the Rotterdam experience with more than 1000 patients. Eur J Nucl Med 1993;20:716-31.

65. Krenning EP, Kwekkeboom DJ, Oei HY, et al. Somatostatin-receptor scintigraphy in gastroenteropancreatic tumors. An overview of European results. Ann N Y Acad Sci 1994; 733:416-24.

66. Reubi JC, Krenning EP, Lamberts SWJ, et al. In vitro detection of somatostatin receptors in human tumours. Metabolism 1992:41(9):104-10.

67. Reubi JC, Laissue J, Krenning EP, et al. Somatostatin receptors in human cancer: incidence, characteristics, functional correlates and clinical implication. J Steroid Biochem Mol Biol 1992;43:27-35.

68. Pearse AGE, Polak JM, Health CM. Polypeptide hormone production by carcinoid apudomas and their relevant cytochemistry. Virchows Arch [B] 1974;16:95-109.

69. Reubi JC, Maurer R, Klijn JG, et al. High incidence of somatostatin receptors in human meningiomas: biochemical characterization. J Clin Endocrinol Metab 1986;63:433-8.

70. Reubi JC, Lang W, Maurer R, et al. Distribution and biochemical characterization of somatostatin receptors in tumours of the human central nervous system. Cancer Res 1987; 47:5758-65.

71. Kwekkeboom DJ, Reubi JC, Lamberts SWJ, et al. In vivo somatostatin receptor imaging in medullary thyroid carcinoma. J Clin Endocrinol Metab 1993;76:1413-17.

72. Reubi JC, Waser B, Sheppard M, et al. Somatostatin receptors are present in small-cell but not in non-small-cell primary lung carcinomas: relationship to EGF receptors. Int J Cancer 1990;45:269-74.

73. Reubi JC, Waser B, Vanhagen M, et al. In vitro and in vivo detection of somatostatin receptors in human malignant lymphomas. Int $\mathrm{J}$ Cancer 1992;50:895-900.

74. Reubi JC, Horisberger U, Waser B, et al. Preferential location of somatostatin receptors in germinal centers of human gut lymphoid tissue. Gastroenterology 1992;103:1207-14.

75. Goldshmith SJ, Macapinlac HA, O’Brien JP. Somatostatin receptor imaging in lymphoma. Semin Nucl Med 1995; 25:262-71.

76. Reubi JC, Schaer JC, Waser B, et al. Affinity profiles for human somatostatin receptor sst1-sst5 of somatostatin radio-tracers selected for scintigraphic and radiotherapeutic use. Eur J Nucl Med 2000;27:273-82.

77. Kvols LK, Reubi J-C, Horisberger U, et al. The presence of somatostatin receptors in malignant neuroendocrine tumor tissue predicts reponsiveness to octreotide. Yale J Biol Med 1992;65:505-18.

78. Bakker WH, Krenning EP, Breeman WAP, et al. Receptor scintigraphy with radioiodined somatostatin analogue: radiola-beling, purification, biologic activity and in vivo application in animals. J Nucl Med 1990;31:1501-9.

79. Bakker WH, Albert A, Bruns C, et al. [111 In-DTPA-D-Phe1]-octreotide, a potential radiopharmaceutical for imaging of somatostatin receptor-positive tumors: synthesis, radio-labeling and in vitro validation. Life Sci 1991;49:1583-91.

80. Maina T, Stolz B, Albert R, et al. Synthesis, radiochemical and biological evaluation of ${ }^{99 \mathrm{~m}} \mathrm{Tc}[\mathrm{N} 4-(\mathrm{D})$-Phe1] octreotide, a new derivative with high affinity for somatostatin receptors. In: Nicolini M, Bandoli G, Mazzi U, editors. Technetium and rhenium in chemistry and nuclear medicine.New York: Cortina International, Raven; 1995. p. 395-400.

81. Maina T, Stolz B, Albert R, et al. Synthesis, radiochemistry and biological evaluation of a new somatostatin analogue (SZ 219-387) labelled with technetium 99m. Eur J Nucl Med 1994;21:437-44.

82. Gabriel M, Decristoforo C, Donnemiller E, et al. An intra-patient comparison of ${ }^{99 \mathrm{~m}}$ Tc-EDDA/HYNIC-TOC with ${ }^{111}$ In-DTPA-octreotide for diagnosis of somatostatin receptor-expressing tumors. J Nucl Med 2003;44:708-16.

83. Lamberts SWJ, Krenning EP, Reubi J-C. The role of somato-statin and its analogs in the diagnosis and treatment of tumours. Endocr Rev $1991 ; 12: 450-82$

84. Anderson JH, Dehdashti F, Cutler PD, et al. ${ }^{64} \mathrm{Cu}$-TETA-octreotide as a PET imaging agent for patients with neuro-endocrine tumours. J Nucl Med 2001;42:213-21.

85. Ugur O, Kothari PJ, Finn RD, et al. Ga-66 labelled somatosta-tin analogue DOTA-D-Phe1-Tyr3-octreotide as a potential agent for positron emission tomography imaging and receptor mediated internal radiotherapy of somatostatin receptor positive tumours. Nucl Med Biol 2002;29:147-57.

86. Hofmann M, Maecke H, Borner R, et al. Biokinetics an imaging with the somatostatin receptor PET radioligand ${ }^{68}$ Ga-DOTATOC: preliminary data. Eur J Nucl Med 2001; 28:1751-7.

87. Jamar F, Barone R, Mathieu I, et al. ${ }^{86}$ Y-DOTA(0)-D-Phe(1)-Tyr(3)-octreotide (SMT487)—a phase 1 clinical study: phar-macokinetics, biodistribution and renal protective effect of different regimens of amino acid co-infusion. Eur J Nucl Med Mol Imaging 2003;30:510-8. 88. Guhlke S, Wester HJ, Bruns C, et al. 2-[ $\left[{ }^{18} \mathrm{~F}\right]$ fluoropropionyl-D-Phe1-octreotide, a potential radiopharmaceutical for quantitative somatostatin receptor imaging with PET: synthesis, radio-labeling, in vitro validation and biodistribution in mice. Nucl Med Biol 1994;21:819-25

89. Wester HJ, Brockmann J, Rosch F, et al. PET-pharmacokinet-ics of ${ }^{18}$ F-octreotide: a comparison with ${ }^{67}$ Ga-DFO- and ${ }^{86}$ Y-DTPAoctreotide. Nucl Med Biol 1997;24:275-86.

90. Schottelius M, Wester HJ, Reubi JC, et al. Improvement of pharmacokinetics of radioiodinated Tyr(3)-octreotide by conjugation with carbohydrates. Bioconjug Chem 2002;13:1021-30.

91. Wester HJ, Schottelius M, Scheidhauer K, et al. Comparison of radioiodinated TOC, TOCA and Mtr-TOCA: the effect of carbohydration on the pharmacokinetics. Eur J Nucl Med Mol Imaging 2002;29:28-38.

92. Wester HJ, Schottelius M, Scheidhauer K, et al. PET imaging of somatostatin receptors: design, synthesis and preclinical evaluation of a novel ${ }^{18}$ F-labelled, carbohydrated analogue of octreotide. Eur J Nucl Med Mol Imaging 2003;30:117-22.

93. Kong X, Zhu Q, Vidal P, et al. Comparisons of anti-human immunodeficiency virus activities, cellular transport, and plasma and 
intracellular pharmacokinetics of 3'-fluoro-3'-deoxy-thymidine and 3'-azido-3'-deoxythymidine. Antimicrob Agents Chemother 1992;36:808-18.

94. Wilson I, Chatterjee S, Wolf W. The use of 3 '-fluoro-3'-deoxy-thymidine and studies of its ${ }^{18}$ F-radiolabeling, as a tracer for the noninvasive monitoring of the biodistribution of drugs against AIDS. J Fluorine Chem 1991;55:283-9.

95. Grierson J, Shields A, Eary J. Development of a radio-synthesis for 3'- $\left[{ }^{18} \mathrm{~F}\right]$ fluoro-3'-deoxynucleosides. J Label Compd Radiopharm 1997; 10:60-2.

96. Grierson J, Shields A. Radiosynthesis of $3^{\prime}$-deoxy-3'- $\left[{ }^{18} \mathrm{~F}\right]$-fluorothymidine: $\left[{ }^{18} \mathrm{~F}\right] \mathrm{FLT}$ for imaging of cellular proliferation in vivo. Nucl Med Biol 2000;27:143-56.

97. Machulla H, Blocher A, Kuntzsch M, et al. Simplified labeling approach for synthesizing $3^{\prime}$-deoxy- $3^{\prime}-\left[{ }^{18} \mathrm{~F}\right]$ fluorothymi-dine $\left(\left[{ }^{18} \mathrm{~F}\right] \mathrm{FLT}\right)$. J Radioanal Nucl Chem 2000;243:843-6.

98. Wodarski C, Eisenbarth J, Weber K, et al. Synthesis of 3'-deoxy-3'-[ $\left.{ }^{18} \mathrm{~F}\right]$ fluoro-thymidine with $2,3^{\prime}-O$-anhydro-5'-O-(4,4'dimethoxytrityl)thymidine. J Label Compd Radio-pharm 2000;43:1211-8.

99. Martin S, Eisenbarth J, Wagner-Utermann U, et al. $\left[{ }^{18} \mathrm{~F}\right] \mathrm{FLT}:{ }^{18} \mathrm{~F}$ labeling of 3-Boc-1-(2-deoxy-3-O-nosyl-5-O-trityl-b-Dlyxofuranosyl)thymine and other thymine derivatives. J Nucl Med 2000;41:255P.

100. Martin S, Eisenbarth J, Wagner-Utermann U, et al. A new precursor for the radiosynthesis of $\left[{ }^{18}\right.$ F]FLT. Nucl Med Biol 2002;29:26373.

101. Belt J, Marina N, Phelps D, et al. Nucleoside transport in normal and neoplastic cells. Adv Enzyme Regul 1993; 33:235-52.

102. Coppock D, Pardee A. Control of thymidine kinase mRNA during the cell cycle. Mol Cell Biol 1987;7:2925-32.

103. Gross M, Merrill G. Regulation of thymidine kinase protein levels during myogenic withdrawal from the cell cycle is independent of mRNA regulation. Nucl Acids Res 1988; 16:11625-43.

104. Sherley J, Kelly T. Regulation of human thymidine kinase during the cell cycle. J Biol Chem 1988;263:8350-8.

105. Ito M, Conrad S. Independent regulation of thymidine kinase mRNA and enzyme levels in serum-stimulated cells. J Biol Chem 1990;265:6954-60.

106. Bartrek J, Bartkova J, Lukas J. The retinoblastoma protein pathway and the restriction point. Curr Opin Cell Biol 1996;8:805-14.

107. Ewen M. The cell cycle and the retinoblastoma protein family. Cancer Metastasis Rev 1994;13:45-66.

108. Sherr CD. Type cyclins. Trends Biol Sci 1995;20:187-90.

109. Sherr C, Roberts J. Inhibitors of mammalian G1 cycline-dependent kinases. Genes Dev 1995;9:1149-63.

110. Weinberg R. The retinoblastoma protein and cell cycle control. Cell 1995;81:323-30.

111. Hengstschlager M, Knofler M, Mullner E, et al. Different regulation of thymidine kinase during the cell cycle of normal versus DNA tumor virus-transformed cells. J Biol Chem 1994;269:13836-42.

112. Hengstschlager M, Oliver P, Hengstshlager-Ottnad E, et al. Loss of the p16/MTS1 tumor suppressor gene causes E2F-mediated deregulation of essential enzymes of the DNA precursor metabolism. DNA Cell Biol 1996;15:41-51.

113. Hengstschlager M, Hengstshlager-Ottnad E, Oliver P, et al. The role of p16 in the E2F-dependent thymidine kinase regulation. Oncogene 1996;12:1635-43.

114. Toyohara J, Waki A, Takamatsu S, et al. Basis of FLT as cell proliferattion marker: comparative uptake studies with $\left[{ }^{3} \mathrm{H}\right]$ thymidine and $\left.{ }^{3} \mathrm{H}\right]$ arabinothymidine, and cell-analysis in 22 asynchronously growing tumor cell lines. Nucl Med Biol 2002;29:281-7.

115. Shields A, Grierson J, Dohmen B, et al. Imaging proliferation in vivo with [F-18]FLT and positron emission tomography. Nat Med 1998;4:1334-6.

116. Eriksson S, Kierdaszuk B, Mucnh-Peterson B, et al. Comparison of the substate specificities of human thymidiine kinase 1 and 2 and deoxycytidine kinase toward antiviral and cytostatic nucleoside analogs. Biochem Biophys Res Commun 1991;176:586-92.

117. Nottebrock H, Then R. Thymidine concentrations in serum and urine of different animal species and man. Biochem Pharmacol 1977;26:2175-9.

118. Mier W, Haberkorn U, Eisenhut M. [ ${ }^{18}$ F]FLT; portrait of a proliferation marker. Eur J Nucl Med Mol Imaging 2002;29:165-9.

119. Wagner M, Seitz U, Buck A, et al. $3{ }^{\prime}$ - $\left[{ }^{18} \mathrm{~F}\right]$ fluoro-3'-deoxy-thymidine $\left(\left[{ }^{18} \mathrm{~F}\right]\right.$-FLT) as positron emission tomography tracer for imaging proliferation in a murine B-cell lymphoma model and in the human disease. Cancer Res 2003; 63:2681-7.

120. Seitz U, Wagner M, Neumaier B, et al. Evaluation of pyrimi-dine metabolising enzymes and in vitro uptake of $3{ }^{\prime}-\left[{ }^{18} \mathrm{~F}\right]$ fluoro- $3{ }^{\prime}-$ deoxythymidine $\left(\left[{ }^{18} \mathrm{~F}\right] \mathrm{FLT}\right)$ in pancreatic cancer cell lines. Eur J Nucl Med Mol Imaging 2002; 29:1174-81.

121. Vesselle H, Grierson J, Peterson LM, et al. ${ }^{18} \mathrm{~F}$-fluorothymi-dine radiation dosimetry in human PET imaging studies. J Nucl Med 2003;44:1482-8.

122. Buck AK, Schirrmeister H, Hetzel M, et al. 3-Deoxy-3-[ $\left.{ }^{18}\right]$ fluorothymidine-positron emission tomography for non-invasive assessment of proliferation in pulmonary nodules. Cancer Res 2002;62:3331-4.

123. Buck AK, Halter G, Schirrmeister H, et al. Imaging proliferation in lung tumors with PET: ${ }^{18}$ F-FLT versus ${ }^{18}$ F-FDG. J Nucl Med 2003;44:1426-31.

124. Dittmann H, Dohmen BM, Paulsen F, et al. $\left[{ }^{18} \mathrm{~F}\right]$ FLT PET for diagnosis and staging of thoracic tumours. Eur J Nucl Med Mol Imaging 2003;30:1407-12.

125. Francis DL, Visvikis D, Costa DC, et al. Potential impact of $\left[{ }^{18} \mathrm{~F}\right] 3^{\prime}$-deoxy-3'-fluorothymidine versus $\left[{ }^{18} \mathrm{~F}\right]$ fluoro-2-deoxy-D-glucose in positron emission tomography for colo-rectal cancer. Eur J Nucl Med Mol Imaging 2003;30:988-94.

126. Francis DL, Freeman A, Visvikis D, et al. In vivo imaging of cellular proliferation in colorectal cancer using positron emission tomography. Gut 2003;52:1602-6.

127. Barthel H, Cleij MC, Collingridge DR, et al. $3^{\prime}$-deoxy- $3^{\prime}-\left[{ }^{18} \mathrm{~F}\right]$ fluorothymidine as a new marker for monitoring tumor response to antiproliferative therapy in vivo with positron emission tomography. Cancer Res 2003;63:3791-8.

128. Dittmann H, Dohmen BM, Kehlbach R, et al. Early changes in $\left[{ }^{18} \mathrm{~F}\right] \mathrm{FLT}$ uptake after chemotherapy: an experimental study. Eur J Nucl Med Mol Imaging 2002;29:1462-9.

129. Shields AF, Dohmen BM, Mangner TJ, et al. Use of F-18-FLT for imaging gastrointestinal tumors. J Nucl Med 2001; $42: 108$.

130. Carter EA, McKuster K, Syed S, et al. Comparison of (FLT)-F-18 with (18)FDG for differentiation between tumor and focal sites of infection in rats. J Nucl Med 2002; 43:1074

131. Wald LL, Nelson SJ, Day MR, et al. Serial proton magnetic resonance spectroscopy imaging of glioblastoma multiforme after brachytherapy. J Neurosurg 1997;87:525-34.

132. Tedeschi G, Lundbom N, Raman R, et al. Increased choline signal coinciding with malignant degeneration of cerebral gliomas: a serial proton magnetic resonance spectroscopy imaging study. J Neurosurg 1997;87:516-24.

133. Hara T. ${ }^{18}$ F-fluorocholine: a new oncologic PET tracer. J Nucl Med 2001;42:1815-6.

134. Hara T, Kosaka N, Kondo T, et al. Imaging of brain tumor, lung cancer, esophagus cancer, colon cancer, prostate cancer, and bladder cancer with $\left({ }^{11} \mathrm{C}\right)$ choline. J Nucl Med 1997; 38(Suppl):250P.

135. Hara T, Kosaka N, Shinoura N, et al. PET imaging of brain tumor with [methyl- ${ }^{11}$ C]choline. J Nucl Med 1997;38:842-7.

136. Hara T, Inagaki K, Kosaka N, et al. Sensitive detection of mediastinal lymph nodes metastasis of lung cancer with ${ }^{11} \mathrm{C}$-choline PET. J Nucl Med 2000;41:1507-13. 
137. Kobori O, Kirihara N, Kosaka N, et al. Positron emission tomography of esophagal carcinoma using ${ }^{11} \mathrm{C}$-choline and ${ }^{18} \mathrm{~F}$ fluorodeoxyglucose. Cancer 1999;1999:1638-48.

138. Hara T, Kosaka N, Kishi H. PET imaging of prostate cancer using carbon-11-choline. J Nucl Med 1998;39:990-5.

139. Hara T, Yuasa M. Automated synthesis of fluorine-18 labeled choline analog: 2-fluoroethyl-dimethyl-2-oxyethylammonium. J Nucl Med 1997;38(Suppl):44P.

140. DeGrado TR, Coleman RE, Wang S, et al. Synthesis and evaluation of ${ }^{18} \mathrm{~F}$-labeled choline as an oncologic tracer for positron emission tomography: initial findings in prostate cancer. Cancer Res 2000;61:110-7.

141. DeGrado TR, Baldwin SW, Wang S, et al. Synthesis and evaluation of ${ }^{18}$ F-labeled choline analogs as oncologic PET tracers. J Nucl Med 2001;42:1805-14.

142. DeGrado TR, Reiman RE, Price DT, et al. Pharmacokinetics and radiation dosimetry of ${ }^{18}$ F-fluorocholine. J Nucl Med 2002;43:92-6. 143. Hara T. ${ }^{11} \mathrm{C}$-choline and 2-deoxy-2- $\left[{ }^{18} \mathrm{~F}\right]$ fluoro-D-glucose in tumor imaging with positron emission tomography. Mol Imaging Biol 2002;4:267-73

144. Hara T, Kosaka N, Kishi H. Development of ${ }^{18} \mathrm{~F}$-fluoroethyl-choline for cancer imaging with PET: synthesis, biochemistry, and prostate cancer imaging. J Nucl Med 2002; 43:187-99.

145. Price DT, Coleman RE, Liao RP, et al. Comparison of $\left[{ }^{18} \mathrm{~F}\right]$ fluorocholine and $\left[{ }^{18} \mathrm{~F}\right]$ fluorodeoxyglucose for positron emission tomography of androgen dependent and androgen independent prostate cancer. J Urol 2002;168:273-80.

146. Yorek MA, Dunlap JA, Spector AA, et al. Effect of ethanol-amine on choline uptake and incorporation into phosphati-dylcholine in human Y79 retinoblatoma cells. J Lipid Res 1986;27:1205-13.

147. Rosen MA, Jones RM, Yano Y, et al. Carbon-11 choline: synthesis, purification, and brain uptake inhibition by 2dimethylaminoethanol. J Nucl Med 1985;26:1424-8.

148. Wyss MT, Weber B, Honer M, et al. ${ }^{18} \mathrm{~F}$-choline in experimental soft tissue infection assessed with autoradiography and high-resolution PET. Eur J Nucl Med Mol Imaging 2004;31:312-6.

149. Kiesewetter DO, Kilbourn MR, Landvatter SW, et al. Preparation of four fluorine- 18-labeled estrogens and their selective uptakes in target tissues of immature rats. J Nucl Med 1984;25:1212-21.

150. Jonson SD, Bonasera TA, Dehdashti F, et al. Comparative breast tumor imaging and comparative in vitro metabolism of $16 \alpha-$

$\left[{ }^{18} \mathrm{~F}\right]$ fluoroestradiol-17 $\beta$ and $16 \beta-\left[{ }^{18} \mathrm{~F}\right]$ fluoromoxestrol in isolated hepatocytes. Nucl Med Biol 1999; 26:123-30.

151. Brandes SJ, Katzenellenbogen JA. Fluorinated androgens and progestins: molecular probes for androgen and progesterone receptors with potential use in positron emission tomography. Mol Pharmacol 1987;32:391-403.

152. Liu A, Carlson KE, Katzenellenbogen JA. Synthesis of high affinity fluorine-substituted ligands for the androgen receptor. Potential agents for imaging prostatic cancer by positron emission tomography. J Med Chem 1992;35:2113-29.

153. Noé G, Cheng YC, Dabiké M, et al. Tissue uptake of human sex hormone-binding globuline an its influence on ligand kinetics in the adult female rat. Biol Reprod 1992;47:970-6.

154. Seimbille Y, Rousseau J, Benard F, et al. ${ }^{18} \mathrm{~F}$-labeled difluo-roestradiols: preparation and preclinical evaluation as estrogen receptorbinding radiopharmaceuticals. Steroids 2002; 67:765-75.

155. Romer J, Fuchtner F, Steinbach J, et al. Automated production of $16 \alpha-\left[{ }^{18} \mathrm{~F}\right]$ fluoroestradiol for breast cancer imaging. Nucl Med Biol 1999;26:473-9.

156. Mathias CJ, Welch MJ, Katzenellenbogen JA, et al. Characterization of the uptake of $16 \alpha-\left(\left[{ }^{18}\right.\right.$ F $]$ fluoro)-17 $\beta$-estradiol in DMBAinduced mammary tumors. Int J Rad Appl In-strum B 1987;14(1):15-25.

157. Mankoff DA, Tewson TJ, Eary JF. Analysis of blood clearance and labeled metabolites for the estrogen receptor tracer [F-18]-16 $\alpha$ fluoroestradiol (FES). Nucl Med Biol 1997; 24:341-8.

158. Tewson TJ, Mankoff DA, Peterson LM, et al. Interactions of $16 \alpha-\left[{ }^{18} \mathrm{~F}\right]$-fluoroestradiol (FES) with sex steroid binding protein (SBP).

Nucl Med Biol 1999;26:905-13.

159. Pomper MG, VanBrocklin H, Thieme AM, et al. 11 $\beta$-Me-thoxy-, $11 \beta$-ethyl- and $17 \alpha$-ethynyl-substitued 16 $\alpha$-fluo-roestradiols: receptor-based imaging agents with enhanced uptake efficiency and selectivity. J Med Chem 1990; 33:3143-55.

160. Mintun MA, Welch MJ, Siegel BA, et al. Breast cancer: PET imaging of estrogen receptors. Radiology 1988;169:45-8.

161. Dehdashti F, Mortimer JE, Siegel BA, et al. Positron tomo-graphic assessment of estrogen receptors in breast cancer: comparison with FDG-PET and in vitro receptor assays. J Nucl Med 1995;36:1766-74.

162. Katzenellenbogen JA, Mathias CJ, VanBrocklin HF, et al. Titration of the in vivo uptake of $16 \alpha-\left[{ }^{18} \mathrm{~F}\right]$ fluoroestradiol by target tissues in the rat: competition by tamoxifen, and implications for quantitating estrogen receptors in vivo and the use of animal models in receptorbinding radiopharmaceuti-cal development. Nucl Med Biol 1993;20:735-45.

163. McGuire AH, Dehdashti F, Siegel BA, et al. Positron tomo-graphic assessment of $16 \alpha-\left[{ }^{18} \mathrm{~F}\right]$ fluoro-17ß-estradiol uptake in metastatic breast carcinoma. J Nucl Med 1991; 32:1526-31.

164. Flanagan FL, Dehdashti F, Siegel BA. PET in breast cancer. Semin Nucl Med 1998;28:290-302.

165. Dehdashti F, Flanagan FL, Mortimer JE, et al. Positron emission tomographic assessment of "metabolic flare" to predict response of metastatic breast cancer to antiestrogen therapy. Eur J Nucl Med 1999;26:51-6.

166. Romer J, Fuchtner F, Steinbach J, et al. Automated synthesis of $16 \alpha-\left[{ }^{18} \mathrm{~F}\right]$ fluoroestradiol-3,17 $\beta$-disulphamate. Appl Ra-diat Isot 2001;55:631-9.

167. Lim JL, Zheng L, Berridge MS, et al. The use of 3-methoxymethyl-16 $\beta$, 17 $\beta$-epiestriol- $O$-cyclic sulfone as the precursor in the synthesis of F-18 16 $\alpha$-fluoroestradiol. Nucl Med Biol 1996;23:911-5.

168. Rodig H, Brust P, Romer J, et al. Distribution of estrone sulfatase in rat brain determined by in vitro autoradiography with $16 \alpha-$ $\left[{ }^{18} \mathrm{~F}\right]$ fluoroestradiol-3,17 $\beta$-disulfamate. Appl Ra-diat Isot 2002;56:773-80.

169. Brust P, Rodig H, Romer J, et al. Distribution of $16 \alpha-\left[{ }^{18} \mathrm{~F}\right]$ fluoro-estradiol-3,17 $\beta$-disulfamate in rats, tumour-bearing mice and piglets. Appl Radiat Isot 2002;57:687-95.

170. Pomper MG, Katzenellenbogen JA, Welch MJ, et al. 21-[ $\left[{ }^{18} \mathrm{~F}\right]$ fluoro-16 $\alpha$-ethyl-19-norprogesterone: synthesis and target tissue selective uptake of a progestin receptor based radiotracer for positron emission tomography. J Med Chem 1988;31:1360-3.

171. Verhagen A, Luurtsema G, Pesser JW, et al. Preclinical evaluation of a positron emitting progestin ([ $\left.{ }^{18} \mathrm{~F}\right]$ fluoro-16 $\alpha$-methyl-19norprogesterone) for imaging progesterone receptor positive tumours with positron emission tomography. Cancer Lett 1991;59:125-32. 172. Verhagen A, Luurtsema G, Pesser JW, et al. Preclinical evaluation of a positron emitting progestin ([ $\left.{ }^{18} \mathrm{~F}\right]$ fluoro-16 $\alpha$-methyl-19norprogesterone) for imaging progesterone receptor positive tumours with positron emission tomography. Cancer Lett 1991;59:125-32. 173. Pomper MG, Katzenellenbogen JA, Welch MJ, et al. 21-[ $\left.{ }^{18} \mathrm{~F}\right]$ fluoro-16 $\alpha$-ethyl-19-norprogesterone: synthesis and target tissue selective uptake of a progestin receptor based radiotracer for positron emission tomography. J Med Chem 1988;31:1360-3.

174. Verhagen A, Elsinga PH, de Groot TJ, et al. A fluorine-18 labeled progestin as an imaging agent for progestin receptor positive tumors with positron emission tomography. Cancer Res 1991;51:1930-3.

175. Dehdashti F, McGuire AH, Van Brocklin HF, et al. Assessment of 21-[ $\left.{ }^{18} \mathrm{~F}\right]$ fluoro-16 $\alpha$-ethyl-19-norprogesterone as a positron-emitting radiopharmaceutical for the detection of progestin receptors in human breast carcinomas. J Nucl Med 1991;32:1532-7.

176. Verhagen A, Studeny M, Luurtsema G, et al. Metabolism of a $\left[{ }^{18} \mathrm{~F}\right]$ fluorine labeled progestin $\left(21-\left[{ }^{18} \mathrm{~F}\right]\right.$ fluoro-16 $\alpha$-ethyl-19- 
norprogesterone) in humans: a clue for future investigations. Nucl Med Biol 1994;21:941-52.

177. Choe YS, Bonasera TA, Chi DY, et al. $6[\alpha]-\left[{ }^{18} \mathrm{~F}\right]$ fluoroproges-terone: synthesis via halofluorination-oxidation, receptor binding and tissue distribution. Nucl Med Biol 1995; 22:635-42.

178. Kochanny MJ, VanBrocklin HF, Kym PR, et al. Fluorine-18-labeled progestin ketals: synthesis and target tissue uptake selectivity of potential imaging agents for receptor-positive breast tumors. J Med Chem 1993;36:1120-7.

179. Kym PR, Carlson KE, Katzenellenbogen JA. Progestin 16 $\alpha, 17 \alpha$-dioxolane ketals as molecular probes for the progesterone receptor: synthesis, binding affinity, and photochemical evaluation. J Med Chem 1993;36:1111-9.

180. Buckman BO, Bonasera TA, Kirschbaum KS, et al. Fluorine-18-labeled progestin 16 $\alpha$, 17 $\alpha$-dioxolanes: development of high-affinity ligands for the progesterone receptor with high in vivo target site selectivity. J Med Chem 1995;38:328-37.

181. Liu AJ, Katzenellenbogen JA, VanBrocklin HF, et al. $20-\left[{ }^{18} \mathrm{~F}\right]$ fluoromibolerone, a positron-emitting radiotracer for androgen receptors: synthesis and tissue distribution studies. J Nucl Med 1991;32:81-8.

182. Pertschuk LP, Rosenthal HE, Macchia RJ. Correlation of histochemical an biochemical analysis of androgen binding in prostatic cancer: relation to therapeutic cancer. Cancer 1982;49:984-93.

183. Mobbs BG, Johnson IE. Basal and estrogen-stimulated hormone receptor profiles in four R3327 rat prostatic carcinoma sublines in relation to histopathology and androgen sensitivity. Cancer Res 1988;48:3077-83.

184. Ekman P, Snochowski M, Dahlberg E, et al. Steroid receptors in metastatic carcinoma of the human prostate. Eur J Cancer

$1979 ; 15: 257-62$.

185. Blankestein MA, Bolt-de-Vries J, van Aubel OGJM, et al. Hormone receptors in human prostate cancer. Scand. J Urol Nephrol 1988; Suppl 10:39-45.

186. Liu AJ, Dence CS, Welch MJ, et al. Fluorine-18-labeled androgens: radiochemical synthesis and tissue distribution studies on six fluorine-subsituted androgens, potential imaging agents for prostatic cancer. J Nucl Med 1992;33:724-34.

187. Bonasera TA, O’Neil JP, Xu M, et al. Preclinical evaluation of fluorine-18-labeled androgen receptor ligands in baboons. J Nucl Med 1996;37:1009-15.

188. Downer JB, Jones LA, Engelbach JA, et al. Comparison of animal models for the evaluation of radiolabeled androgens. Nucl Med Biol 2001;28:613-26.

189. Labaree DC, Hoyte RM, Nazareth LV, et al. $7 \alpha$-iodo and $7 \alpha$-fluoro steroids as androgen receptor mediated imaging agent. J Med Chem 1999;3:2021-34.

190. Garg PK, Labaree DC, Hoyte RM, et al. $\left[7[\alpha]-{ }^{18}\right.$ F $]$ fluoro- $17[\alpha]$-methyl-5[ $\left.\alpha\right]$-dihydrotestosterone: a ligand for andro-gen receptormediated imaging of prostate cancer. Nucl Med Biol 2001;28:85-90.

191. Wang GL, Semenza GL. Characterization of hypoxia-inducible factor 1 and regulation of DNA binding activity by hypoxia. J Biol Chem 1993;268:21513-8.

192. Hockel M, Schlenger K, Aral B, et al. Association between tumor hypoxia and malignant progression in advanced cancer of the uterine cervix. Cancer Res 1996;56:4509-15.

193. Hlatky L, Tsionou C, Hanhfeldt P, et al. Mammary fibro-blasts may influence breast tumor angiogenesis, via hypox-ia-induced vascular endothelial growth factor upregulation and protein expression. Cancer Res 1994;54:6083-6.

194. Graeber TG, Osmanian C, Jacks T, et al. Hypoxia-mediated selection of cells with diminished apoptotic potential in solid tumours. Nature 1996;379:88-91.

195. Rice GC, Ling V, Schimke RT. Frequencies of independent and simultaneous selection of Chinese hamster cells for methotrexate and doxorubicin (adriamycin) resistance. Proc Natl Acad Sci USA 1987;84:9261-4.

196. Rice GC, Hoy C, Schimke RT. Transient hypoxia enhances the frequency of dihydrofolate reductase gene amplification in Chinese hamster ovary cells. Proc Natl Acad Sci USA 1986;83:5978-82.

197. Teicher BA. Physiologic mechanisms of therapeutic resistance. Hematol Oncol Clin North Am 1995;9:475-506.

198. Brizel DM, Sibley GS, Prosnitz LR, et al. Tumor hypoxia adversely affects the prognosis of carcinoma of the head and neck. Int J Radiat Oncol Biol Phys 1997;38:285-9.

199. Gatenby RA, Kessler HB, Rosenblum JS, et al. Oxygen distribution in squamous cell carcinoma metastases and its relationship to outcome of radiation therapy. Int J Radiat Oncol Biol Phys 1988;14:831-8.

200. Brizel DM, Scully SP, Harrelson JM, et al. Tumor oxygen-ation predicts for the likelihood of distant metastases in human soft tissue sarcoma. Cancer Res 1996;56:941-3.

201. Moulder JE, Rockwell S. Hypoxic fractions of solid tumors: experimental techniques, methods of analysis, and a survey of existing data. Int J Radiat Oncol Biol Phys 1984; 10:695-712.

202. Chapman JD, Baer K, Lee J. Characteristics of the metabolism-induced binding of misonidazole to hypoxic mammalian cells. Cancer Res 1983;43:1523-8.

203. Ballinger JR. Imaging hypoxia in tumors. Semin Nucl Med 2001;31:321-9.

204. Cater DB, Silver IA. Quantitative measurements of oxygen tension in normal tissues and in tumors of patients before and after radiotherapy. Acta Radiol 1960;53:233-56.

205. Bentzen L, Keiding S, Horsman MR, et al. Assessment of hypoxia in experimental mice tumours by [ $\left.{ }^{18} \mathrm{~F}\right]$ fluo-romisonidazole PET and $\mathrm{pO}_{2}$ electrode measurements. Influence of tumour volume and carbogen breathing. Acta Oncol 2002;41:304-12.

206. Nordsmark M, Overgaard M, Overgaard J. Pretreatment oxygenation predicts radiation response in advanced squa-mous cell carcinoma of the head and neck. Radiother Oncol 1996;41:31-9.

207. Nordsmark M, Bentzen SM, Overgaard J. Measurement of human tumour oxygenation status by a polarographic needle electrode. An analysis of inter- and intratumour heterogeneity. Acta Oncol 1994;33:383-9.

208. Chapman JD, Schneider RF, Urbain JL, et al. Single photon emission computed tomography and positron-emission tomography assays for tissue oxygenation. Semin Radiat Oncol 2001;11:47-57.

209. Chapman JD, Franko AJ, Sharplin J. A marker for hypoxic cells in tumours with potential clinical applicability. Br J Cancer

1981;43:546-50.

210. Chapman JD. Hypoxic sensitizers: implications for radiation therapy. N Engl J Med 1979;301:1429-32.

211. Workman P Keynote. Bioreductive mechanisms. Int J Radiat Oncol Biol Phys 1992;22:631-7.

212. Chapman JD, Lee J, Meeker BE. Adduct formation by 2-nitroimidazole drugs in mammalian cells: optimization of markers for tissue oxygenation. In: Adams GE, Breccia A, Fielden EM, Wardman P, editors. Selective activation of drugs by redox processes. New York: Plenum; 1990. p. 313-23.

213. Chapman JD, Baer K, Lee J. Characteristics of the metabolism-induced binding of misonidazole to hypoxic mammalian cells. Cancer Res 1983;43:1523-8.

214. Yang DJ, Wallace S, Cherif A, et al. Development of F-18-labeled fluoroerythronitroimidazole as a PET agent for imaging tumor hypoxia. Radiology 1995; 194:795- 800.

215. Lord EM, Harwell L, Koch CJ. Detection of hypoxic cells by monoclonal antibody recognizing 2-nitroimidazole adducts. Cancer Res $1993 ; 53: 5721-6$ 
216. Raleigh JA, Miller GG, Franko AJ, et al. Fluorescence im-munohistochemical detection of hypoxic cells in spheroids and tumours. Br J Cancer 1987;56:395-400

217. Raleigh JA, Franko AJ, Kelly DA, et al. Development of an in vivo ${ }^{19} \mathrm{~F}$ magnetic resonance method for measuring oxygen deficiency in tumors. Magn Reson Med 1991; 22:451-66.

218. Rasey JS, Grunbaum Z, Magee S, et al. Characterization of radiolabeled fluoromisonidazole as a probe for hypoxic cells. Radiat Res 1987;111:292-304.

219. Seddon BM, Maxwell RJ, Honess DJ, et al. Validation of the fluorinated 2-nitroimidazole SR-4554 as a noninvasive hypoxia marker detected by magnetic resonance spectros-copy. Clin Cancer Res 2002;8:2323-35.

220. Hodgkiss RJ, Jones G, Long A, et al. Flow cytometric evaluation of hypoxic cells in solid experimental tumours using fluorescence immunodetection. Br J Cancer 1991;63:119-25.

221. Chapman JD, Engelhardt EL, Stobbe CC, et al. Measuring hypoxia and predicting tumor radioresistance with nuclear medicine assays. Radiother Oncol 1998;46:229-37.

222. Koh WJ, Bergman KS, Rasey JS, et al. Evaluation of oxy-genation status during fractionated radiotherapy in human nonsmall cell lung cancers using [F-18]fluoromisonidazole positron emission tomography. Int J Radiat Oncol Biol Phys 1995;33:391-8

223. Koh WJ, Rasey JS, Evans ML, et al. Imaging of hypoxia in human tumors with [F-18]fluoromisonidazole. Int J Radiat Oncol Biol Phys 1992:22:199-212.

224. Rasey JS, Koh WJ, Evans ML, et al. Quantifying regional hypoxia in human tumors with positron emission tomography of $\left[{ }^{18}\right.$ F]fluoromisonidazole: a pretherapy study of 37 patients. Int J Radiat Oncol Biol Phys 1996;36:417-28.

225. Urtasun RC, McEwan AJ, Parliament MB, et al. Measurement of hypoxia in human tumors by SPECT imaging of iodoazomycin arabinoside. Br J Cancer 1996;74:209-12.

226. Parliament MB, Chapman JD, Urtasun RC, et al. Non-invasive assessment of human tumour hypoxia with ${ }^{123}$ I-iodoa-zomycin arabinoside: preliminary report of a clinical study. Br J Cancer 1992;65:90-5.

227. Grierson JR, Link JM, Mathis CA, et al. A radiosynthesis of fluorine-18 fluoromisonidazole. J Nucl Med 1989;30:343-50.

228. Piert M, Machulla H, Becker G, et al. Introducing fluorine-18 fluoromisonidazole positron emission tomography for the localisation and quantification of pig liver hypoxia. Eur J Nucl Med 1999;26:95-109.

229. Lim JL, Berridge MS. An efficient radiosynthesis of $\left[{ }^{18} \mathrm{~F}\right]$ fluoromisonidazole. Appl Radiat Isot 1993;44:1085-91.

230. Cherif A, Yang DJ, Tansey W, et al. Rapid synthesis of $3-\left[{ }^{18} \mathrm{~F}\right]$ fluoro-1-(2'-nitro- $1^{\prime}$-imidazolyl)-2-propanol ([ $\left[{ }^{18} \mathrm{~F}\right]$ flu-oromisonidazole). Pharm Res 1994;11:466-9.

231. Rasey JS, Koh WJ, Grierson JR, et al. Radiolabelled fluo-romisonidazole as an imaging agent for tumor hypoxia. Int J Radiat Oncol Biol Phys 1989;17:985-91.

232. Rasey JS, Nelson NJ, Chin L, et al. Characteristics of the binding of labeled fluoromisonidazole in cells in vitro. Radiat Res 1990;122:301-8.

233. Casciari JJ, Rasey JS. Determination of the radiobiologically hypoxic fraction in multicellular spheroids from data on the uptake of $\left[{ }^{3} \mathrm{H}\right]$ fluoromisonidazole. Radiat Res 1995;141:28- 36.

234. Casciari JJ, Graham MM, Rasey JS. A modeling approach for quantifying tumor hypoxia with [F-18]fluoromisonida-zole PET timeactivity data. Med Phys 1995;22:1127-39.

235. Rasey JS, Casciari JJ, Hofstrand PD, et al. Determining hypoxic fraction in a rat glioma by uptake of radiolabeled fluoromisonidazole. Radiat Res 2000;153:84-92.

236. Piert M, Machulla HJ, Becker G, et al. Dependency of the $\left[{ }^{18} \mathrm{~F}\right]$ fluoromisonidazole uptake on oxygen delivery and tissue oxygenation in the porcine liver. Nucl Med Biol 2000;27:693-700.

237. Koh WJ, Rasey JS, Evans ML, et al. Imaging of hypoxia in human tumors with [F-18]fluoromisonidazole. Int J Radiat Oncol Biol Phys 1992;22:199-212.

238. Valk PE, Mathis CA, Prados MD, et al. Hypoxia in human gliomas: demonstration by PET with fluorine-18-fluo-romisonidazole. J Nucl Med 1992:33:2133-7.

239. Martin GV, Caldwell JH, Graham MM, et al. Noninvasive detection of hypoxic myocardium using fluorine-18-fluo-romisonidazole and positron emission tomography. J Nucl Med 1992;33:2202-8.

240. Yeh SH, Liu RS, Wu LC, et al. Fluorine-18 fluoromisonida-zole tumour to muscle retention ratio for the detection of hypoxia in nasopharyngeal carcinoma. Eur J Nucl Med 1996;23:1378-83.

241. Rajendran JG, Wilson DC, Conrad EU, et al. $\left[{ }^{18} \mathrm{~F}\right] \mathrm{FMISO}$ and $\left[{ }^{18} \mathrm{~F}\right]$ FDG PET imaging in soft tissue sarcomas: correlation of hypoxia, metabolism and VEGF expression. Eur J Nucl Med Mol Imaging 2003;30:695-704.

242. Koh WJ, Bergman KS, Rasey JS, et al. Evaluation of oxy-genation status during fractionated radiotherapy in human nonsmall cell lung cancers using [F-18]fluoromisonidazole positron emission tomography. Int J Radiat Oncol Biol Phys 1995;33:391-8.

243. Bentzen L, Keiding S, Horsman MR, et al. Feasibility of detecting hypoxia in experimental mouse tumours with ${ }^{18} \mathrm{~F}-\mathrm{fluorinated} \mathrm{tracers}$ and positron emission tomography—a study evaluating [ ${ }^{18}$ F $]$ fluoro-2-deoxy-D-glucose. Acta Oncol 2000;39:629-37.

244. Gronroos T, Eskola O, Lehtio K, et al. Pharmacokinetics of $\left[{ }^{18}\right.$ F]FETNIM: a potential marker for PET. J Nucl Med 2001;42:1397-404

245. Lehtio K, Oikonen V, Gronroos T, et al. Imaging of blood flow and hypoxia in head and neck cancer: initial evaluation with $\left[{ }^{15} \mathrm{O}\right] \mathrm{H}_{2} \mathrm{O}$ and $\left[{ }^{18}\right.$ F]fluoroerythronitroimidazole PET. J Nucl Med 2001;42:1643-52.

246. Tolvanen T, Lehtio K, Kulmala J, et al. ${ }^{18} \mathrm{~F}$-fluoroerythroni-troimidazole radiation dosimetry in cancer studies. J Nucl Med 2002;43:1674-80.

247. Lehtio K, Oikonen V, Nyman S, et al. Quantifying hypoxia with fluorine-18 fluoroerythronitrimidazole ([ ${ }^{18}$ F $]$ FETNIM) and PET using the tumour to plasma ratio. Eur J Nucl Med Mol Imaging 2003;30:101-8.

248. Patlak CS, Blasberg RG. Graphical evaluation of blood-to-brain transfer constants to multiple-time uptake data. J Cereb Blood Flow Metab 1985;5:584-90.

249. Logan J. Graphical analysis of PET data applied to reversible and irreversible tracers. Nucl Med Biol 2000; 27:661-70.

250. Rasey JS, Hofstrand PD, Chin LK, et al. Characterization of $\left[{ }^{18} \mathrm{~F}\right]$ fluoroetanidazole, a new radiopharmaceutical for detecting tumor hypoxia. J Nucl Med 1999;40:1072-9.

251. Kachur AV, Dolbier WR Jr, Evans SM, et al. Synthesis of new hypoxia markers EF1 and $\left[{ }^{18}\right.$ F]-EF1. Appl Radiat Isot 1999;51:643-50.

252. Evans SM, Joiner B, Jenkins WT, et al. Identification of hypoxia in cells and tissues of epigastric 9L rat glioma using EF5 [2-(2-nitro-

1H-imidazol-1-yl)- $N$-(2,2,3,3,3-pentafluoro-propyl) acetamide]. Br J Cancer 1995;72:875-82.

253. Evans SM, Jenkins WT, Joiner B, et al. 2-Nitroimidazole (EF5) binding predicts radiation resistance in individual 9L s.c. tumors. Cancer Res 1996;56:405-11.

254. Koch CJ, Evans SM, Lord EM. Oxygen dependence of cellular uptake of EF5 [2-(2-nitro-1H-imidazol-1-yl)- $N$-(2,2,3,3,3-

pentafluoropropyl)acetamide]: analysis of drug adducts by fluorescent antibodies vs bound radioactivity. Br J Cancer 1995;72:869-74.

255. Dolbier WRJ, Li A-R, Koch CJ, et al. $\left[{ }^{18} \mathrm{~F}\right]-\mathrm{EF} 5$, a marker for PET detection of hypoxia: synthesis of precursor and a nex fluorination procedure. Appl Radiat Isot 2001;54:73-80.

256. Ziemer LS, Evans SM, Kachur AV, et al. Noninvasive imaging of tumor hypoxia in rats using the 2-nitroimidazole ${ }^{18}$ F-EF5. Eur J Nucl 
Med Mol Imaging 2003;30:259-66.

257. Evans SM, Kachur AV, Shiue CY, et al. Noninvasive detection of tumor hypoxia using the 2-nitroimidazole $\left[{ }^{18} \mathrm{~F}\right] \mathrm{EF} 1 . \mathrm{J}$ Nucl Med 2000;41:327-36

258. Yamamoto F, Aoki M, Furusawa Y, et al. Synthesis and evaluation of 4-bromo-1-(3-[ ${ }^{18}$ F]fluoropropyl)-2-nitroimida-zole with a low energy LUMO orbital designed as brain hypoxia-targeting imaging agent. Biol Pharm Bull 2002; 25:616-21.

259. Blau M, Nagler W, Bender MA. Fluorine-18: a new isotope for bone scanning. J Nucl Med 1962;3:332-4

260. Galasko CSB. The pathological basis for skeletal scintigra-phy. J Bone Joint Surg Br 1975;57:353-9.

261. Messa C, Goodman WG, Hoh CK, et al. Bone metabolic activity measured with positron emission tomography and $\left[{ }^{18} \mathrm{~F}\right]$ fluoride ion in renal osteodystrophy: correlation with bone histomorphometry. J Clin Endocrinol Metab 1993; 77:949-55.

262. Berger F, Lee YP, Loening AM, et al. Whole-body skeletal imaging in mice utilizing micro-PET: optimization of repro-ducibility and applications in animal models of bone disease. Eur J Nucl Med Mol Imaging 2002;29:1225-36.

263. Petren-Mallmin M. Clinical and experimental imaging of breast cancer metastases in the spine. Acta Radiol Suppl 1994;391:1-23.

264. Petren-Mallmin M, Andreasson I, Ljunggren O, et al. Skeletal metastases from breast cancer: uptake of ${ }^{18} \mathrm{~F}$-fluoride measured with positron emission tomography in correlation with CT. Skeletal Radiol 1998;27:72-6.

265. Schirrmeister H, Guhlmann A, Kotzerke J. Early detection and accurate description of extent of metastatic bone disease in breast cancer with fluoride ion and positron emission tomography. J Clin Oncol 1999;17:2381-9.

266. Schirrmeister H, Guhlmann A, Elsner K. Sensitivity in detecting osseous lesions depends on anatomic localization: planar bone scintigraphy versus ${ }^{18}$ F PET. J Nucl Med 1999;40:1623-9.

267. Schirrmeister H, Glatting G, Hetzel J, et al. Prospective evaluation of the clinical value of planar bone scans, SPECT, and ${ }^{18} \mathrm{~F}-\mathrm{labeled}$

NaF PET in newly diagnosed lung cancer. J Nucl Med 2001;42:1800-4.

268. Heidelberger C. Fluorinated pyrimidines, a new class of tumor-inhibitory compounds. Nature 1957;179:663-6.

269. Heidelberger C. Fluorinated pyrimidines. Prog Nucleic Acid Res Mol Biol 1965;4:1-50.

270. Vine EN, Young D, Vine WH, et al. An improved synthesis of ${ }^{18}$ F-5-fluorouracil. Int J Appl Radiat Isot 1979; 30:401-5.

271. Fowler JS, Finn RD, Lambrecht RM, et al. The synthesis of ${ }^{18}$ F-5-fluorouracil. VII. J Nucl Med 1973;14:63-4.

272. Wiley AL Jr, Ramirez G, Johnson RO, et al. Treatment of carcinoma of base of tongue with radiation therapy and 5-fluorouracil. Potential for optimization with ${ }^{18}$ F-FU. Acta Radiol Oncol Radiat Phys Biol 1979;18:235-43.

273. Shani J, Wolf W. A model for prediction of chemotherapy response to 5-fluorouracil based on the differential distribution of 5-

$\left.{ }^{18} \mathrm{~F}\right]$ fluorouracil in sensitive versus resistance lymphocytic leukemia in mice. Cancer Res 1977;37:2306-8.

274. Shani J, Wolf W, Schlesinger T, et al. Distribution of ${ }^{18} \mathrm{~F}-5$-fluorouracil in tumor-bearing mice and rats. Int J Nucl Med Biol 1978;5:19-28.

275. Lieberman LM, Wessels BW, Wiley AL Jr, et al. ${ }^{18} \mathrm{~F}-5$-fluo-rouracil studies in humans and animals. Int J Radiat Oncol Biol Phys 1980;6:505-9.

276. Neirinckx RD, Lambrecht RM, Wolf AP. Cyclotron isotopes and radiopharmaceuticals XXV. An anhydrous ${ }^{18}$ F-fluorinat-ing intermediate: trifluoromethyl hypoflurite. Int J Appl Ra-diat Isot 1978;29:323-7.

277. Visser GWM, Boele S, Van Halteren BW, et al. Mechanism and stereochemistry of the fluorination of uracil and cyto-sine using fluorine and acetyl hypofluorite. J Org Chem 1986;51:1466-71.

278. Visser GWM, Herder RE, De Kanter FJJ, et al. Fluorination of pyrimidines. Part 2. Mechanistic aspects of the reaction of acetyl hypofluorite with uracil and cytosine derivatives. J Chem Soc Perkin Trans I 1988;1203-7.

279. Visser WMG, Gorree GCM, Braakhuis BJM, et al. An optimized synthesis of ${ }^{18} \mathrm{~F}$-labelled-5-fluorouracil and a reevalu-ation of its use as a prognostic agent. Eur J Nuc Med 1989;15:225-9.

280. Brown G, Brady F, Roberts AD, et al. Improved radiosyn-thesis of 5- $\left[{ }^{18} \mathrm{~F}\right]$ fluorouracil. J Label Compd Radiopharm 1999;42(Suppl 1):S533-5.

281. Ishiwata K, Ido T, Kawashima K, et al. Studies on ${ }^{18} \mathrm{~F}$-la-beled pyrimidines. II. Metabolic investigation of ${ }^{18} \mathrm{~F}-5$-fluo-rouracil, ${ }^{18} \mathrm{~F}-5$ fluoro-2'-deoxyuridine and ${ }^{18}$ F-5-fluorouri-dine in rats. Eur J Nucl Med 1984;9:185-9.

282. Ishiwata $\mathrm{K}$, Ido $\mathrm{T}$, Abe $\mathrm{Y}$, et al. Studies on ${ }^{18} \mathrm{~F}$-labeled pyrimidines. III. Biochemical investigation of ${ }^{18} \mathrm{~F}$-labeled pyrimidines and comparison with ${ }^{3} \mathrm{H}$-deoxythymidine in tumor-bearing rats and mice. Eur J Nucl Med 1985; 10(1-2):39-44.

283. Shani J, Young D, Schlesinger T, et al. Dosimetry and preliminary human studies of ${ }^{18} \mathrm{~F}-5$-fluorouracil. Int J Nucl Med Biol 1982; 9:25-35.

284. Shani J, Manaka RC, Young D, et al. Comparative radio-pharmacokinetics of ${ }^{18} \mathrm{~F}$-5-fluorouracil administered i.v. to rats bearing a mammary tumor. Int J Nucl Med Biol 1985;12:9-12.

285. Baker SD. Pharmacology of fluorinated pyrimidines: enilu-racil. Invest New Drugs 2000;18:373-81.

286. Bading JR, Alauddin MM, Fissekis JD, et al. Blocking ca-tabolism with eniluracil enhances PET studies of 5-[ $\left.{ }^{18} \mathrm{~F}\right] \mathrm{flu}-\mathrm{orouracil}$ pharmacokinetics. J Nucl Med 2000;41:1714-24.

287. Visser GW, van der Wilt CL, Wedzinga R, et al. ${ }^{18} \mathrm{~F}$-radio-pharmacokinetics of $\left[{ }^{18} \mathrm{~F}\right]$-5-fluorouracil in a mouse bearing two colon tumors with a different 5-fluorouracil sensitivity: a study for a correlation with oncological results. Nucl Med Biol 1996;23:333-42. 288. Young D, Vine E, Ghanbarpour A, et al. Metabolic and distribution studies with radiolabeled 5-fluorouracil. Nuk-learmedizin $1982 ; 21: 1-7$

289. Hohenberger P, Strauss LG, Lehner B, et al. Perfusion of colorectal liver metastases and uptake of fluorouracil assessed by H2(15)O and $\left[{ }^{18}\right.$ F]uracil positron emission tomography (PET). Eur J Cancer 1993;29A:1682-6.

290. Port RE, Strauss LG, Clorius JH. Positron emission tomography following brief infusion of 5- $\left[{ }^{18} \mathrm{~F}\right]$ uracil: linear model for the kinetics of ${ }^{18} \mathrm{~F}$ radioactivity in tumors. Onkologie 1989;12(Suppl 1):51-2.

291. Dimitrakopoulou A, Strauss LG, Clorius JH, et al. Studies with positron emission tomography after systemic administration of fluorine18-uracil in patients with liver metastases from colorectal carcinoma. J Nucl Med 1993;34:1075-81.

292. Dimitrakopoulou-Strauss A, Strauss LG, Schlag P, et al. Fluorine-18-fluorouracil to predict therapy response in liver metastases from colorectal carcinoma. J Nucl Med 1998; 39:1197-202.

293. Kissel J, Brix G, Bellemann ME, et al. Pharmacokinetic analysis of $5-\left[{ }^{18} \mathrm{~F}\right]$ fluorouracil tissue concentrations measured with positron emission tomography in patients with liver metastases from colorectal adenocarcinoma. Cancer Res 1997; 57:3415-23.

294. Moehler M, Dimitrakopoulou-Strauss A, Gutzler F, et al. ${ }^{18} \mathrm{~F}$-labeled fluorouracil positron emission tomography and the prognoses of colorectal carcinoma patients with metas-tases to the liver treated with 5-fluorouracil. Cancer 1998; 83:245-53.

295. Saleem A, Yap J, Osman S, et al. Modulation of fluorouracil tissue pharmacokinetics by eniluracil: in vivo imaging of drug action. Lancet 2000; 355:2125-31.

296. Aboagye EO, Saleem A, Cunningham VJ, et al. Extraction of 5-fluorouracil by tumor and liver: a noninvasive positron emission tomography study of patients with gastrointestinal cancer. Cancer Res 2001; 61:4937-41.

297. Haubner R, Kuhnast B, Mang C, Weber WA, Kessler H, Wester HJ, Schwaiger M. $\left[{ }^{18}\right.$ F]Galacto-RGD: synthesis, ra-diolabeling, metabolic stability, and radiation dose estimates. Bioconjug Chem 2004; 15:61-9.

298. Haubner R, Wester HJ, Weber WA, Mang C, Ziegler SI, Goodman SL, Senekowitsch-Schmidtke R, Kessler H, Schwaiger M. 
Published in: European journal of nuclear medicine and molecular imaging (2004), vol. 31, iss. 8, pp. 1182-1206 Status: Postprint (Author's version)

Noninvasive imaging of alpha(v)beta3 inte-grin expression using ${ }^{18} \mathrm{~F}$-labeled RGD-containing glycopep-tide and positron emission tomography. Cancer Res 2001; 61:1781-5.

299. Chen X, Park R, Tohme M, Shahinian AH, Bading JR, Conti PS. MicroPET and autoradiographic imaging of breast cancer alpha vintegrin expression using ${ }^{18} \mathrm{~F}$ - and ${ }^{64} \mathrm{Cu}$-labeled RGD peptide. Bioconjug Chem 2004; 15:41-9. 